\title{
BSDF generation procedures for daylighting systems
}

\section{White paper}

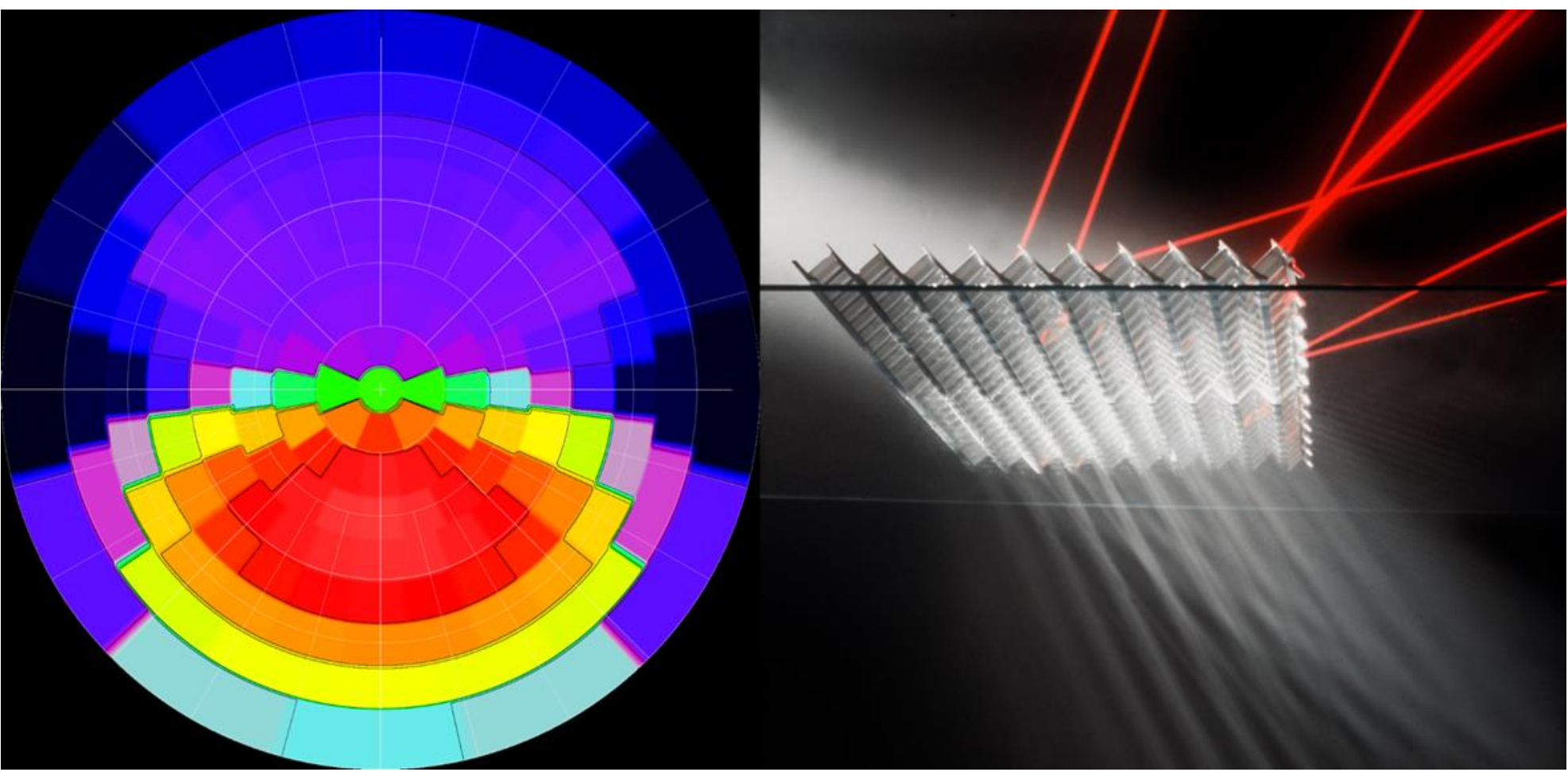

IEA SHC Task 61 / EBC Annex 77: Integrated Solutions for Daylighting and Electric Lighting 


\section{IEA Solar Heating and Cooling Technology Collaboration Programme (IEA SHC)}

The Solar Heating and Cooling Technology Collaboration Programme was founded in 1977 as one of the first multilateral technology initiatives ("Implementing Agreements") of the International Energy Agency. Its mission is "To enhance collective knowledge and application of solar heating and cooling through international collaboration to reach the goal set in the vision of solar thermal energy meeting $50 \%$ of low temperature heating and cooling demand by $2050 . "$

The members of the IEA SHC collaborate on projects (referred to as Tasks) in the field of research, development, demonstration (RD\&D), and test methods for solar thermal energy and solar buildings.

Research topics and the associated Tasks in parenthesis include:

- Solar Space Heating and Water Heating (Tasks 14, 19, 26, 44, 54)

- Solar Cooling (Tasks 25, 38, 48, 53, 65)

- Solar Heat for Industrial or Agricultural Processes (Tasks 29, 33, 49, 62, 64)

- Solar District Heating (Tasks 7, 45, 55)

- Solar Buildings/Architecture/Urban Planning (Tasks 8, 11, 12, 13, 20, 22, 23, 28, 37, 40, 41, 47, $51,52,56,59,63,66)$

- Solar Thermal \& PV (Tasks 16, 35, 60)

- Daylighting/Lighting (Tasks 21, 31, 50,61)

- Materials/Components for Solar Heating and Cooling (Tasks 2, 3, 6, 10, 18, 27, 39)

- Standards, Certification, and Test Methods (Tasks 14, 24, 34, 43, 57)

- Resource Assessment (Tasks 1, 4, 5, 9, 17, 36, 46)

- Storage of Solar Heat (Tasks 7, 32, 42, 58)

In addition to our Task work, other activities of the IEA SHC include our:

> International Conference on Solar Heating and Cooling for Buildings and Industry

$>$ SHC Solar Academy

$>$ Solar Heat Worldwide annual statics report

$>$ Collaboration with solar thermal trade associations

\section{Country Members}

$\begin{array}{lll}\text { Australia } & \text { France } & \text { South Africa } \\ \text { Austria } & \text { Germany } & \text { Spain } \\ \text { Belgium } & \text { Italy } & \text { Sweden } \\ \text { Canada } & \text { Netherlands } & \text { Switzerland } \\ \text { China } & \text { Norway } & \text { Turkey } \\ \text { Denmark } & \text { Portugal } & \text { United Kingdom } \\ \text { European Commission } & \text { Slovakia } & \end{array}$

\section{Sponsor Members}

European Copper Institute

ECREEE

International Solar Energy Society

RCREEE

CCREEE

SACREEE

EACREEE

For more information on the IEA SHC work, including many free publications, please visit www.iea-shc.org. 


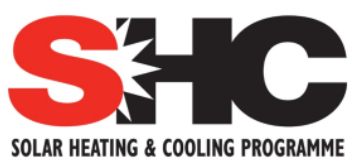

SOLAR HEATING \& COOLNG PROGRAMME INTERNATIONAL ENERGY AGENCY

\title{
BSDF generation procedures for daylighting systems
}

\section{White paper}

\author{
Authors: \\ David Geisler-Moroder, Eleanor S. Lee, Gregory Ward, \\ Bruno Bueno, Lars O. Grobe, Taoning Wang, \\ Bertrand Deroisy, Helen Rose Wilson
}

2021-01-20

T61.C.2.1 - A Technical Report of Subtask C DOI: 10.18777/ieashc-task61-2021-0001

The contents of this report do not necessarily reflect the viewpoints or policies of the International Energy Agency (IEA) or its member countries, the IEA Solar Heating and Cooling Technology Collaboration Programme (SHC TCP) members or the participating researchers.

Cover image left: (C) Bartenbach $\mathrm{GmbH}$, cover image right: (C) Peter Bartenbach 
AUTHORS (in alphabetical order)

Bruno BUENO

Fraunhofer Institute for Solar Energy Systems Heidenhofstr. 2,

79110 Freiburg i. Br.

Germany

bruno.bueno@ise.fraunhofer.de

\section{Bertrand DEROISY}

Belgian Building Research Institute

Avenue P. Holoffe 21

1342 Limelette

Belgium

bertrand.deroisy@bbri.be

David GEISLER-MORODER

Bartenbach $\mathrm{GmbH}$

Rinner Strasse 14

6071 Aldrans

Austria

david.geisler-moroder@bartenbach.com

\section{Lars Oliver GROBE}

Lucerne University of Applied Sciences and Arts

Technikumstrasse 21

6048 Horw

Switzerland

larsoliver.grobe@hslu.ch
Eleanor S. LEE

Lawrence Berkeley National Laboratory

1 Cyclotron Road

Berkeley, California 94720

United States of America

eslee@lbl.gov

Taoning WANG

Lawrence Berkeley National Laboratory

1 Cyclotron Road

Berkeley, California 94720

United States of America

taoningwang@lbl.gov

\section{Greg WARD}

Anyhere Software

950 Creston Rd.

Berkeley, California 94708

United States of America

gregoryiward@gmail.com

\section{Helen Rose WILSON}

Fraunhofer Institute for Solar Energy Systems

Heidenhofstr. 2,

79110 Freiburg i. Br.

Germany

helen.rose.wilson@ise.fraunhofer.de 


\section{KEYWORDS}

Bidirectional scattering distribution function (BSDF), daylight system characterization, daylighting, complex fenestration systems, daylight performance metrics.

\section{ACKNOWLEDGEMENTS}

The authors thank their respective funding agencies for supporting their work:

- The work of Fraunhofer ISE was supported by a Fraunhofer ICON Grant.

- BBRI received funding from Vlaio (Flanders) through the project VIS IV Intelligente lichtregelsystemen (H8C.2017.0932).

- The work at Bartenbach $\mathrm{GmbH}$ was supported by the Federal Ministry for Climate Action, Environment, Energy, Mobility, Innovation and Technology (BMK) through the IEA Research Cooperation program managed by the Austrian Research Promotion Agency FFG (project 864136).

- Research at Lucerne University of Applied Sciences and Arts was supported by the Swiss Innovation Agency Innosuisse, grant number 1155000149, as part of the Swiss Competence Center for Energy Research SCCER FEEB\&D.

- The work at LBNL and Anyhere Software was supported by the Assistant Secretary for Energy Efficiency and Renewable Energy, Building Technologies Office of the U.S. Department of Energy under Contract No. DE-AC02-05CH11231, and by the California Energy Commission under the Electric Program Investment Charge (EPIC) Program, Solicitation Number: PON-13301, entitled "Developing A Portfolio of Advanced Efficiency Solutions: Technologies and Approaches for More Affordable and Comfortable Buildings". 


\section{PREFACE}

Lighting accounts for approximately $15 \%$ of the global electric energy consumption and $5 \%$ of greenhouse gas emissions. Growing economies, higher user demands for quality lighting and rebound effects as a result of low priced and more versatile electric lighting continuously still lead to an absolute increase of lighting energy consumption. More light is used, often less consciously.

Especially the electric lighting market but as well the façade, daylighting und building automation sectors have seen significant technological developments in the past decade. However, these sectors still act mainly independent of each other, leaving out big potentials lying in a better technology and market integration. This integration is on the one hand beneficial to providing better user-centred lighting of indoor spaces. On the other hand, it can contribute significantly to the reduction of worldwide electricity consumptions and CO2-emissions, which is in line with several different governmental energy efficiency and sustainability targets.

IEA SHC Task 61 / EBC Annex 77 "Integrated Solutions for Daylighting and Electric Lighting - From component to system efficiency" therefore pursues the goal to support and foster the better integration of electric lighting and daylighting systems including lighting controls with a main focus on the nonresidential sector. This includes the following activities:

- Review relation between user perspective (needs/acceptance) and energy in the emerging age of "smart and connected lighting" for a relevant repertory of buildings.

- Consolidate findings in use cases and "personas" reflecting the behaviour of typical users.

- Based on a review of specifications concerning lighting quality, non-visual effects as well as ease of design, installation and use, provision of recommendations for energy regulations and building performance certificates.

- Assess and increase robustness of integrated daylight and electric lighting approaches technically, ecologically and economically.

- Demonstrate and verify or reject concepts in lab studies and real use cases based on performance validation protocols.

- Develop integral photometric, user comfort and energy rating models (spectral, hourly) as prenormative work linked to relevant bodies: CIE, CEN, ISO. Initialize standardization.

- Provide decision and design guidelines incorporating virtual reality sessions. Integrate approaches into widespread lighting design software.

- Combine competencies: Bring companies from electric lighting and façade together in workshops and specific projects. Hereby support allocation of added value of integrated solutions in the market.

To achieve this goal, the work plan of IEA SHC Task 61 / EBC Annex 77 is organized according to the following four main subtasks, which are interconnected by a joint working group:

- Subtask A:

- Subtask B:

- Subtask C:

- Subtask D:

- Joint Working Group:
User perspective and requirements

Integration and optimization of daylight and electric lighting

Design support for practitioners (Tools, Standards, Guidelines)

Lab and field study performance tracking

Evaluation tool \& VR Decision Guide 


\section{EXECUTIVE SUMMARY}

This white paper summarizes the current state of the art in the field of measurement and simulation characterization of daylighting systems by bidirectional scattering distribution functions (BSDFs) and provides recommendations broken down by classes of systems and use cases. It is the result of collaborative work conducted by members of the IEA SHC Task 61 / EBC Annex 77, Subtask C2. The document describes proposed procedures for:

- measuring angle-dependent transmittance and reflectance properties of daylighting and shading systems, and

- generating tabular BSDF data sets from these measurement data for use as input to simulation tools.

The type of systems considered in this context include transparent systems, homogeneous or small pattern diffusing systems, diffuse or specular blinds and grids, macroscopic prismatic systems, and micro- or nano-structured systems. A complex fenestration system generally consists of a base material ("curtain") to modify thermal and visual transmittance of the building envelope, and auxiliary elements such as mechanical fixing, lateral guides, and control systems. The procedures to determine the scattering properties described in this document apply to a representative central area of the façade system without edge effects.

After an introduction, a description of the scope of the white paper, relevant definitions and a description of commonly used BSDF data resolutions, we describe empirically-based procedures for generating BSDF data sets for façade systems for later use in lighting simulation software. The overall procedure differs for microscopic and macroscopic systems and is therefore divided into these two areas. As different systems require different BSDF data resolutions for different applications, we provide tabulated recommendations for adequate characterization methods and BSDF resolutions for different classes of systems. The classes are clustered according to the optical properties of the systems and according to the resulting requirements for data resolutions. The document closes with a discussion section on still open issues in BSDF characterization of daylighting systems and their application in lighting simulation tools. 


\section{Contents}

Contents

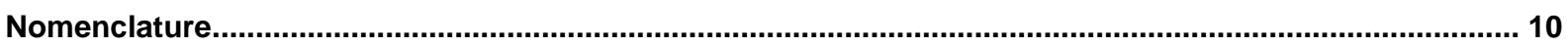

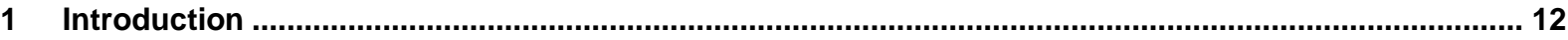

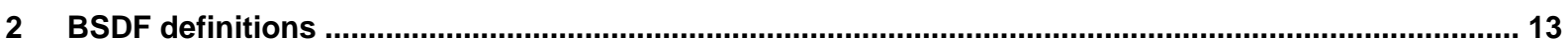

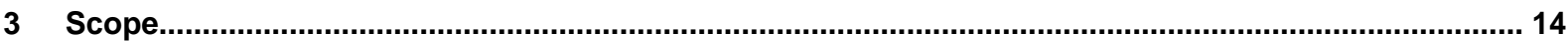

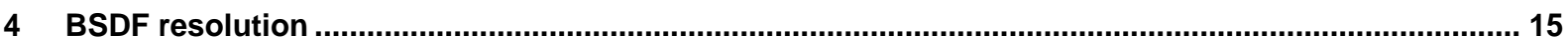

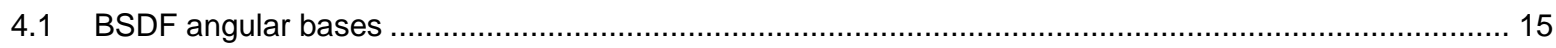

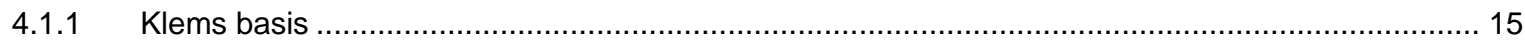

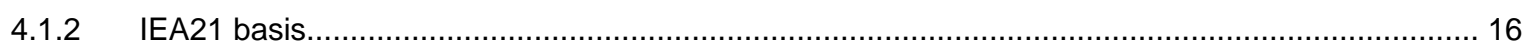

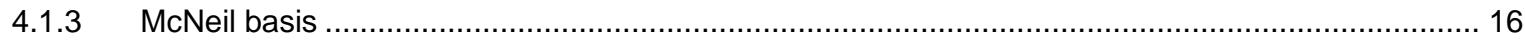

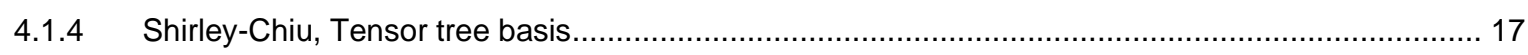

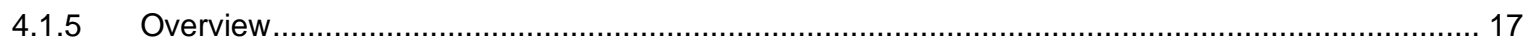

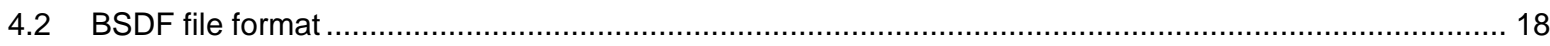

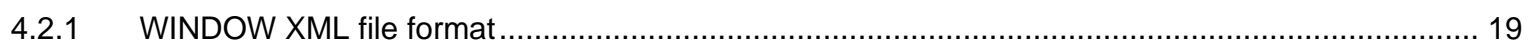

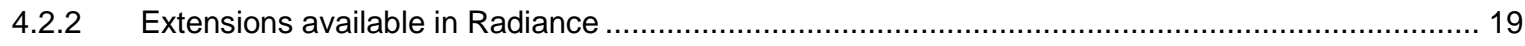

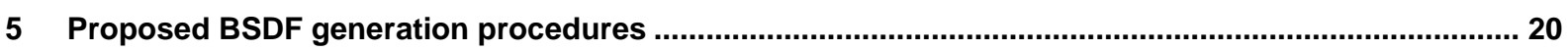

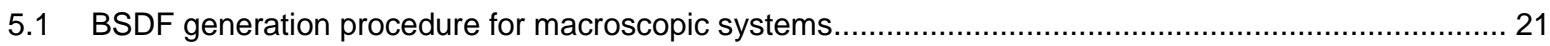

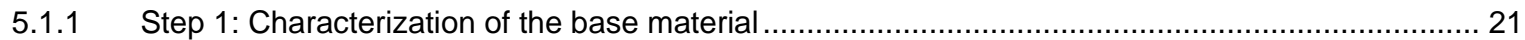

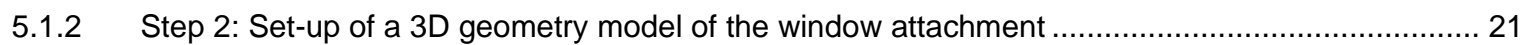

5.1.3 Step 3: Simulation of a tabulated BSDF in the desired resolution using a virtual goniophotometer

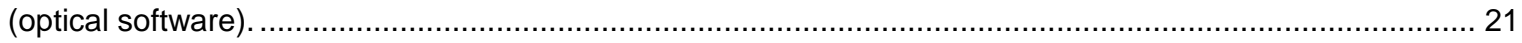

5.1.4 Step 4: Validation of direct-hemispherical transmission values ................................................. 21

5.1.5 Step 5 (optional): Preparation of proxy geometry for inclusion in BSDF XML file ........................... 22

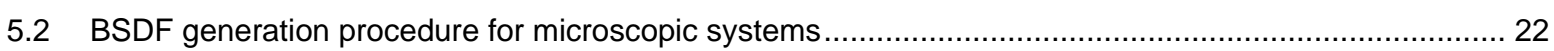

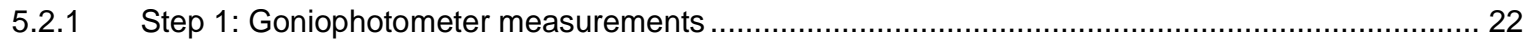

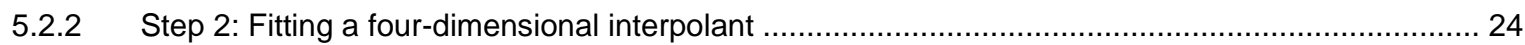

5.2.3 Step 3: Sampling the interpolant model to derive a tabulated BSDF in the desired resolution ........ 25

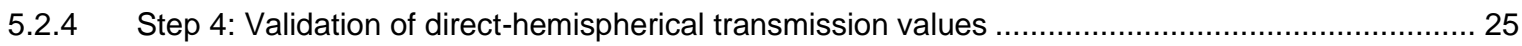

5.3 BSDF generation procedure for microscopic systems: Simplified method for isotropic, non-reflective

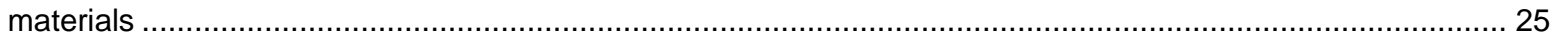

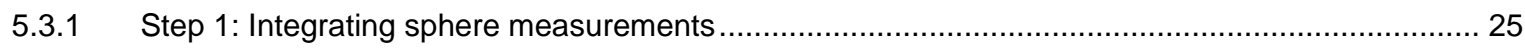

5.3.2 Step 2: Calculate normal-normal transmittance ..................................................................... 26

5.3.3 Step 3: Create a Radiance BRTDfunc model ............................................................................ 26

5.3.4 Step 4: Simulation of a tabulated BSDF in the desired resolution using a virtual goniophotometer

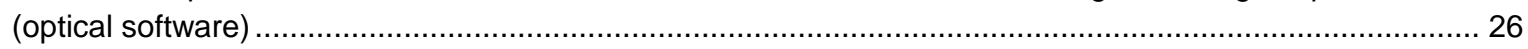

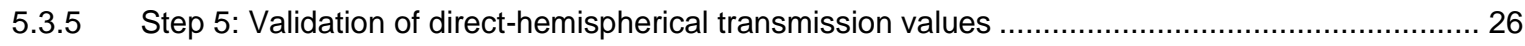

5.3.6 Step 6 (optional): Use the BRTDfunc model as proxy geometry in the simulations .......................... 27

6 Proposed characterization types for various kinds of daylight systems ............................................... 27

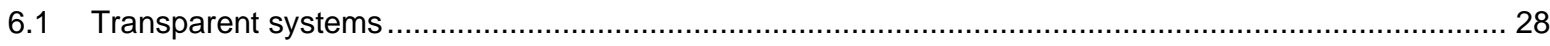

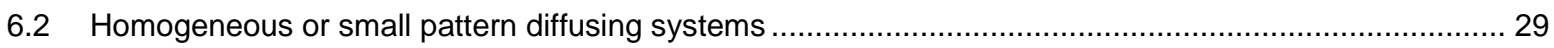




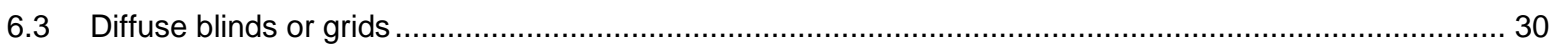

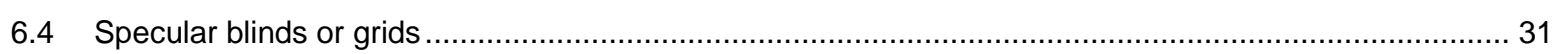

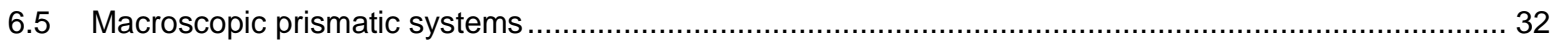

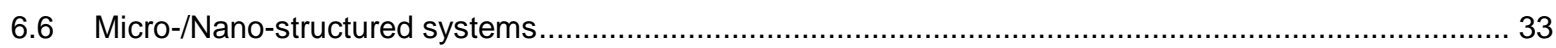

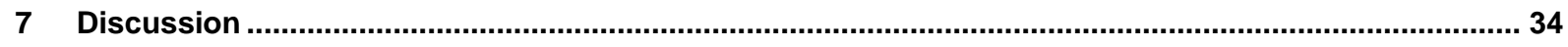

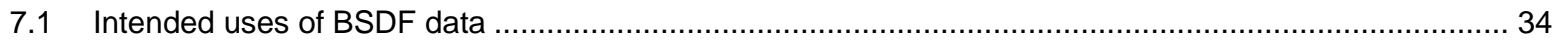

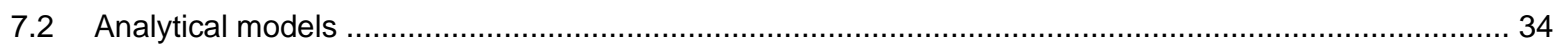

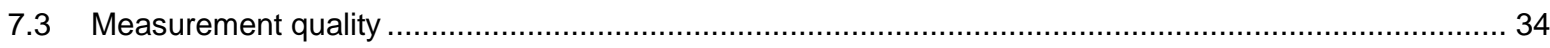

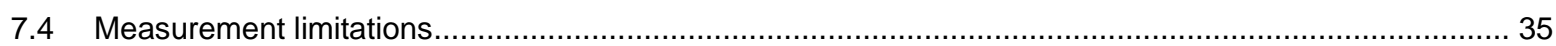

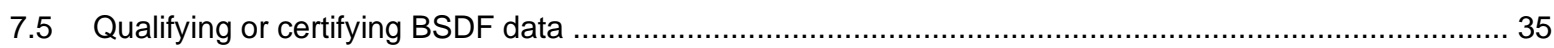

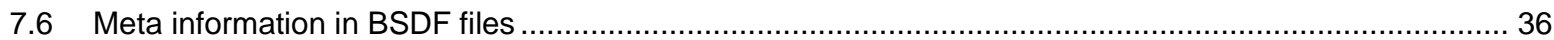

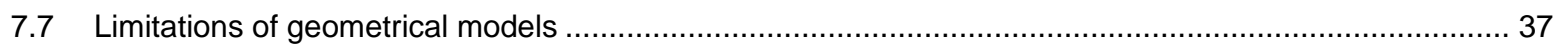

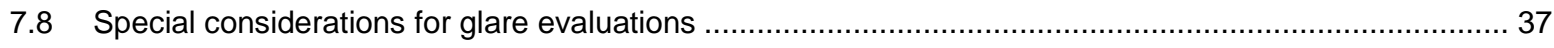

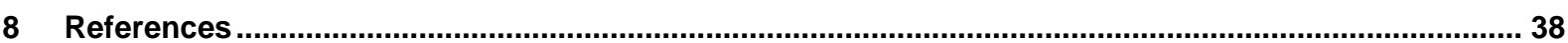




\section{Nomenclature}

\begin{tabular}{|c|c|}
\hline 3PM & $\begin{array}{l}\text { The three-phase method (3PM) [Ward 2011] extends the DC method by } \\
\text { splitting the flux transfer from the sky dome via the facade to the interior in a } \\
\text { three-phase matrix calculation. It thereby facilitates modelling of complex } \\
\text { and dynamic facade systems. }\end{array}$ \\
\hline 5PM & $\begin{array}{l}\text { The five-phase method (5PM) [McNeil 2013] further extends the 3PM } \\
\text { through a separate calculation of the direct solar contribution and thus } \\
\text { improves the accuracy of the direct contribution [Lee 2018]. }\end{array}$ \\
\hline $\begin{array}{l}\text { nalytical BSDF } \\
\text { model }\end{array}$ & $\begin{array}{l}\text { BSDF model described by an analytical function (e.g., Phong, Blinn, Cook- } \\
\text { Torrance, Ashikmin-Shirley, Ward-Geisler-Moroder-Dür, Harvey-Shack, ...) }\end{array}$ \\
\hline BRDF & Bidirectional Reflectance Distribution Function \\
\hline BSDF & Bidirectional Scattering Distribution Function \\
\hline BTDF & Bidirectional Transmittance Distribution Function \\
\hline DC method & $\begin{array}{l}\text { The Daylight Coefficient (DC) method [Bourgeois 2009] is a calculation } \\
\text { method that is based on relative contributions from discretized sky patches } \\
\text { to lighting quantities at (interior) positions. It allows efficient annual daylight } \\
\text { calculations. }\end{array}$ \\
\hline DGP & $\begin{array}{l}\text { The Daylight Glare Probability metric [Wienold and Christoffersen 2006] is } \\
\text { calculated by processing a luminance map of the field of view. It considers } \\
\text { that discomfort glare can be caused by two different effects: (1) a saturation } \\
\text { effect caused by big glare sources (e.g., a window), and (2) a contrast effect } \\
\text { produced by peaky glare sources [Wienold et al. 2019]. }\end{array}$ \\
\hline eDGPs & $\begin{array}{l}\text { The Enhanced Simplified DGP (eDGPs) [Wienold, 2009] is a } \\
\text { computationally efficient alternative to the DGP in which the saturation term } \\
\text { is calculated as proportional to the vertical eye illuminance and the contrast } \\
\text { term is calculated through a simplified image of the field of view. This } \\
\text { simplified image neglects the ambient bounces of light rays, but it has been } \\
\text { shown to preserve the relevant information required by the contrast effect. } \\
\text { Different methods can be used to calculate the vertical illuminance and the } \\
\text { simplified image (e.g., [Abravesh 2019]). }\end{array}$ \\
\hline $\begin{array}{r}\text { High-resolution } \\
\text { BSDF }\end{array}$ & $\begin{array}{l}\text { Tabulated BSDF with basis discretization using hemisphere subdivisions } \\
\text { with average patch sizes covering solid angles corresponding approximately } \\
\text { to cones with opening angles smaller than } 10^{\circ} \text {. }\end{array}$ \\
\hline $\begin{array}{r}\text { Low-resolution } \\
\text { BSDF }\end{array}$ & $\begin{array}{l}\text { Tabulated BSDF with basis discretization using hemisphere subdivisions } \\
\text { with average patch sizes covering solid angles corresponding approximately } \\
\text { to cones with full opening angles of about } 10^{\circ} \text { to } 24^{\circ} \text {. }\end{array}$ \\
\hline system & $\begin{array}{l}\text { A daylighting or shading system that cannot be directly measured with } \\
\text { currently available goniophotometers (i.e., cannot measure a representative } \\
\text { area of the system (e.g., venetian blinds, honeycomb blinds, fabrics with }\end{array}$ \\
\hline
\end{tabular}




\begin{tabular}{|c|c|}
\hline & $\begin{array}{l}\text { arbitrary patterns or surfaces with irregular perforations)). The illuminated } \\
\text { area and transmittance sample aperture should have linear dimensions that } \\
\text { are several times larger (at least a factor of five or better yet ten) than the } \\
\text { linear dimensions of inhomogeneity of the sample. For example, with an } \\
\text { illuminating beam of } 30 \mathrm{~mm} \text { cross-section, the linear dimension of the } \\
\text { repeating period should not be larger than } 6 \mathrm{~mm} \text {, better } 3 \mathrm{~mm} \text {. }\end{array}$ \\
\hline Microscopic system & $\begin{array}{l}\text { A daylight system that can be directly measured with a gonio-photometer, } \\
\text { i.e., that has a structure where the scattering properties can be } \\
\text { characterized correctly from a representative area of the system (e.g., roller } \\
\text { shade fabric, microstructured prismatic film). }\end{array}$ \\
\hline Peak extraction & $\begin{array}{l}\text { Algorithm to identify peaks in the undistorted direct-through direction of a } \\
\text { tabulated BSDF. Based on this, the "vision" component and the unscattered } \\
\text { directly transmitted solar component can be separated in the simulation. For } \\
\text { example, in Radiance the algorithm is implemented in the "aBSDF" material } \\
\text { type [Ward 2018]. }\end{array}$ \\
\hline Tabulated BSDF & $\begin{array}{l}\text { BSDF model described by a discrete set of values for a defined number and } \\
\text { set of directions (i.e., tabulated values of the function) }\end{array}$ \\
\hline $\begin{array}{r}\text { Variable-resolution } \\
\text { BSDF }\end{array}$ & $\begin{array}{l}\text { BSDF with high spatial resolution in the peaky areas of the distribution and } \\
\text { reduced resolution in smooth areas with approximately diffuse behavior } \\
\text { [Ward 2014]. }\end{array}$ \\
\hline
\end{tabular}




\section{Introduction}

This white paper is the result of collaborative work conducted by members of the International Energy Agency (IEA) Solar Heating and Cooling (SHC) Programme Task 61 [IEA 2020], Subtask C2. The white paper describes proposed procedures for:

1) measuring angle-dependent transmittance and reflectance properties of daylighting and shading systems, and then

2) generating bidirectional scattering distribution functions (BSDF) from the measured data for use as input to simulation tools.

The type of systems considered in this document include for example roller blinds, venetian blinds, louvres, prismatic films, and patterned or fritted glazing. A shading system generally consists of a base material ("curtain", [CEN 2018]) provided to modify characteristics such as thermal, visual transmittance of the building envelope, and auxiliary elements such as mechanical fixing, lateral guides, and control systems. The procedures to determine the scattering properties described in this document apply to a representative central area of the façade system without edge effects.

Procedures differ depending on the type of system and intended use of the BSDF data. Output from simulation tools include illuminance and luminance data for the assessment of daylight availability, lighting energy use, visual comfort, indoor environmental quality, and other visual and non-visual performance parameters related to daylight from windows and skylights. Output also includes transmitted solar irradiance which can enable more detailed analysis of thermal comfort and solar loads on indoor surfaces.

The white paper is intended to stimulate discussion and critical review of these procedures internally within the IEA task and then also externally by research and industry. More detailed technical procedures will then be developed by the IEA SHC Task $61 \mathrm{C} 2$ sub-committee from this and other reference sources with the end objective of releasing harmonized procedures to be considered by international standards organizations.

For some classes of products, the described procedures in this document are not intended to be used for each unique variant of the product on the market (e.g., every color of a type of weave of shade fabric). Instead, the procedures are intended to generate a gold standard, empirically based BSDF dataset from which alternate analytical BSDF models could be derived. As an example, an analytical model was developed from spectrophotometer data for solar heat gain simulations of fabrics [Kotey 2009]. Methods for deriving such analytical BSDF models are not included in this document. The procedures also do not include descriptions of how material sample(s) should be obtained in order to adequately represent variations in manufacturing (e.g., required number and selection of samples). Other outstanding technical and procedural issues are raised in the Discussion section for further internal and external review and discussion. 


\section{BSDF definitions}

This section provides a summary of fundamental concepts and term definitions related to BSDFs. For more detailed background information, see [Nicodemus 1977, Lewis 1994].

A bidirectional scattering distribution function (BSDF) $f\left(\theta_{1}, \phi_{1} ; \theta_{2}, \phi_{2}\right)$ describes the scattering properties of a material by specifying the amount of radiance incident from direction $\left(\theta_{1}, \phi_{1}\right)$ that is reflected and/or transmitted in the exiting direction $\left(\theta_{2}, \phi_{2}\right)$ (see Figure 1), i.e., the overall radiance exiting in direction $\left(\theta_{2}, \phi_{2}\right)$ is given as:

$$
L_{2}\left(\theta_{2}, \phi_{2}\right)=\int_{0}^{2 \pi} \int_{0}^{\pi} L_{1}\left(\theta_{1}, \phi_{1}\right) f\left(\theta_{1}, \phi_{1} ; \theta_{2}, \phi_{2}\right)\left|\cos \theta_{1}\right| \sin \theta_{1} d \theta_{1} d \phi_{1}
$$

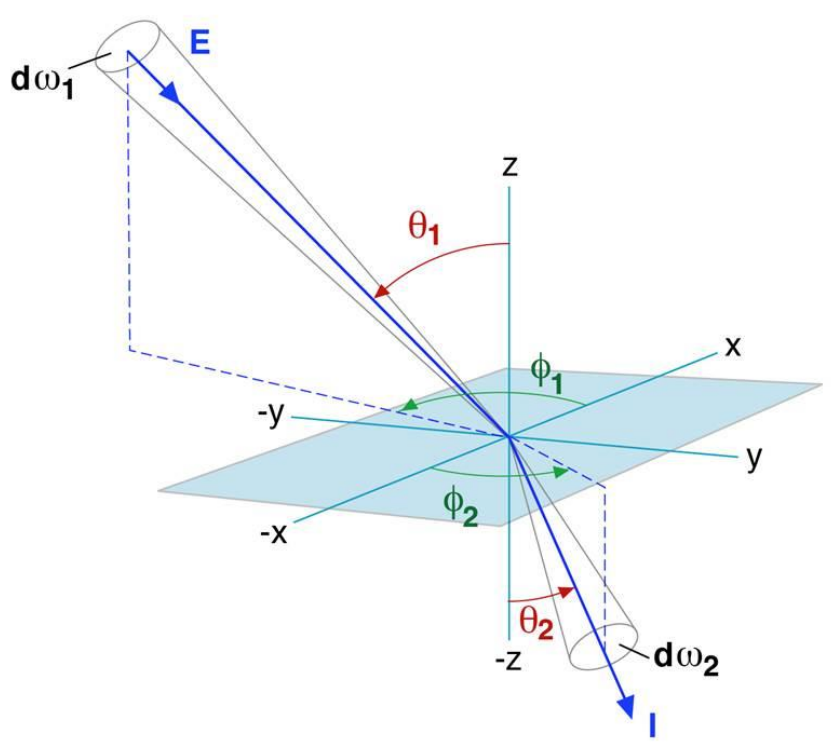

Figure 1. Polar and azimuthal angles of incident and exiting directions. Source: LBNL.

A physically plausible BSDF exhibits three properties:

1. Positivity:

$f\left(\theta_{1}, \phi_{1} ; \theta_{2}, \phi_{2}\right) \geq 0$

2. Helmholtz reciprocity:

$f\left(\theta_{1}, \phi_{1} ; \theta_{2}, \phi_{2}\right)=f\left(\theta_{2}, \phi_{2} ; \theta_{1}, \phi_{1}\right)$

3. Energy conservation:

$a\left(\theta_{1}, \phi_{1}\right)=\int_{0}^{2 \pi} \int_{0}^{\pi} f\left(\theta_{1}, \phi_{1} ; \theta_{2}, \phi_{2}\right)\left|\cos \theta_{2}\right| \sin \theta_{2} d \theta_{2} d \phi_{2} \leq 1$ for all $\left(\theta_{1}, \phi_{1}\right)$

i.e., the overall reflected and transmitted energy is bounded by 1 .

This BSDF definition in four dimensions (two for the incident direction and two for the exiting direction) implicitly assumes spectral uniformity and insensitivity to polarization at least for two broadband spectral ranges (visible with wavelengths from about $380 \mathrm{~nm}$ to $780 \mathrm{~nm}$ and solar from $280 \mathrm{~nm}$ to $4000 \mathrm{~nm}$ ). For typical window attachments in combination with uncoated glazing units, the angular differences in spectral reflection or transmission behavior for finer spectral ranges is negligible, thus this assumption is legitimate in this context. The assumptions need to be re-examined for the combination with coated glazing units. Spectral characterization for analysis of the non-visual effects of lighting and daylighting for atypical materials may be addressed in future work. 
BSDFs contain information about transmission and reflection properties, BTDF and BRDF, respectively. The direct-hemispherical transmission for an incident direction $\left(\theta_{1}, \phi_{1}\right)$ is given by:

$$
\tau\left(\theta_{1}, \phi_{1}\right)=\int_{0}^{2 \pi} \int_{0}^{\pi / 2} f\left(\theta_{1}, \phi_{1} ; \theta_{2}, \phi_{2}\right) \cos \theta_{2} \sin \theta_{2} d \theta_{2} d \phi_{2}
$$

Analytical BSDF models are widely used in computer graphics. As examples, a clear glazing or an ideal mirror are described by Dirac delta functions defining the transmittance or reflectance for the direct transmitted or mirrored direction, respectively, and zero elsewhere. Common models for scattering include the Phong model [Phong 1975], Blinn model [Blinn 1977], Cook-Torrance model [Cook 1981], Ashikmin-Shirley model [Ashikhmin 2000], Ward-Geisler-Moroder-Dür model [GeislerMoroder 2010], and generalized Harvey-Shack model [Krywonos 2011]. These analytical models are widely used for generic material descriptions in simulations, but their assumptions must be reviewed if applied to façade systems different from those initially considered by the models.

In the present context, we are talking about tabulated BSDFs. Here the function $\mathrm{f}\left(\theta_{1}, \phi_{1} ; \theta_{2}, \phi_{2}\right)$ is specified via a discrete set of values for a defined number and set of directions $\left(\theta_{1}\right.$, $\left.\phi_{1} ; \theta_{2}, \phi_{2}\right)$, described as incident and exiting patches $\left(\right.$ patch $_{i}$, patch $\left._{e}\right)$. Typical resolutions are described later in Section 0.

The direct-hemispherical transmission for radiation incident from a patch $i$ is thus given as:

$$
\tau\left(\text { patch }_{i}\right)=\sum_{k=1}^{n} f\left(\text { patch }_{i}, \text { patch }_{k}\right) \Omega_{k}
$$

where $n$ is the number of patches describing the exiting hemisphere and $\Omega_{k}$ is the projected solid angle of atch $_{k}$.

\section{Scope}

The proposed procedures are intended to be used to characterize the light-scattering properties of a single layer, planar window attachment, i.e., an attachment that can be represented as a thin flat surface with analogous light-scattering properties (layer model). This includes systems like clear or translucent glazing, fabrics, films, or blinds. The resulting BSDF is independent of the intended method of installation - interior, exterior (coplanar, or parallel to the window, or non-coplanar, as an overhang or fin), or in the gap of a double- or triple-glazed window. A BSDF for a multi-layer system can be computed from multiple BSDFs in special cases where there is no interdependence between the scattering properties of the single layers. This for example excludes systems where the repeating patterns or "periods" for each attachment layer are the same, e.g., two layers of venetian blinds offset by a half period. To combine attachment BSDFs with additional glazing layers, [WINDOW 2020] enables this calculation with Klems resolution. For variable and high resolution BSDF data, a method for the computational combination has been proposed in [Grobe 2017].

We group window attachment products into two categories - "microscopic" and "macroscopic". This classification has no definition in absolute geometrical dimensions, rather it indicates if a sample of the product can be measured with a goniophotometer directly or if its periodical structure is too large to be correctly captured with such a measurement device. As an example, a scanning goniophotometer with an incident light beam diameter at the sample plane of $30 \mathrm{~mm}$ can be used to directly measure systems like fabrics with typical periodical structures of a few millimeters or less. In contrast, a venetian blind system with $60-\mathrm{mm}$-wide slats spaced $40 \mathrm{~mm}$ apart cannot be measured with such an instrument. 


\section{BSDF resolution}

Tabulated BSDFs are specified via a discrete set of values for a defined number and set of directions $\left(\theta_{1}, \phi_{1} ; \theta_{2}, \phi_{2}\right)$. As an example, they can be generated from discrete measured BSDF data and using an interpolation model [Ward et al. 2014]. The resolution of measured- and tabulated BSDF data needs to match the optical properties of the represented system and the respective application. For example, a prismatic, daylight-redirecting film with pronounced peaks in the scattering distribution requires significantly higher resolution BSDF data than a nearly-Lambertian, translucent panel. Likewise, the calculation of daylight autonomy, which is based on hourly illuminance readings over the year, is less critically dependent on high-resolution BSDF data than the calculation of luminancebased metrics, such as discomfort glare.

For the remainder of this document, we use the nomenclature low-resolution BSDF and highresolution BSDF to refer to tabulated BSDFs as follows:

- BSDF resolutions based on hemisphere subdivisions with average patch sizes covering solid angles corresponding approximately to cones with full opening angles of about $10^{\circ}$ to $24^{\circ}$ are referred to as low-resolution BSDFs.

Examples: Klems, Tregenza, McNeil, Tensor tree with basis resolution 256 patches $\left(=2^{8}\right)$.

- BSDF resolutions with average patch sizes covering solid angles corresponding approximately to cones with full opening angles of smaller than $10^{\circ}$ are described as high-resolution BSDFs. Examples: Tensor tree with basis resolution 1024 patches $\left(=2^{10}\right)$ or more.

\subsection{BSDF angular bases}

Various angular bases for tabulated BSDFs have been defined for various building energy simulation purposes.

\subsubsection{Klems basis}

The Klems $145 \times 145$ subdivision of the incident and exiting hemispheres was initially proposed for solar heat gain calculations [Klems 1994]. See Figure 2.

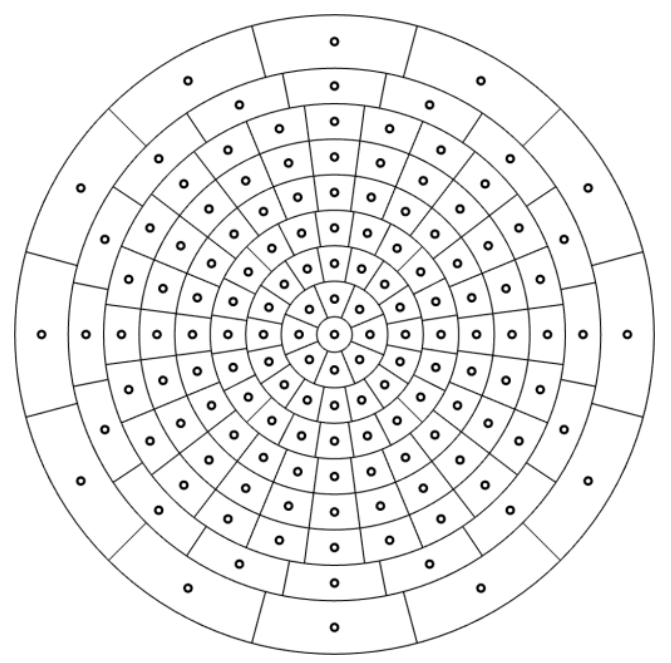

Figure 2. Klems BSDF angular basis [Klems 1994] for incident / exiting hemispheres. 


\subsubsection{IEA21 basis}

Based on the recommended practice for measuring daylight by the Commission Internationale de I'Éclairage [CIE 1994], the International Energy Agency (IEA) SHC Task 21 [IEA 1999] proposed a BSDF angular basis based on incident directions similar to Tregenza's subdivision of the hemisphere and an equidistant angular subdivision in the exiting direction. A common implementation of this format uses $5^{\circ}$ steps in both $\theta$ and $\phi$ angles in the exiting direction (Figure 3 ).
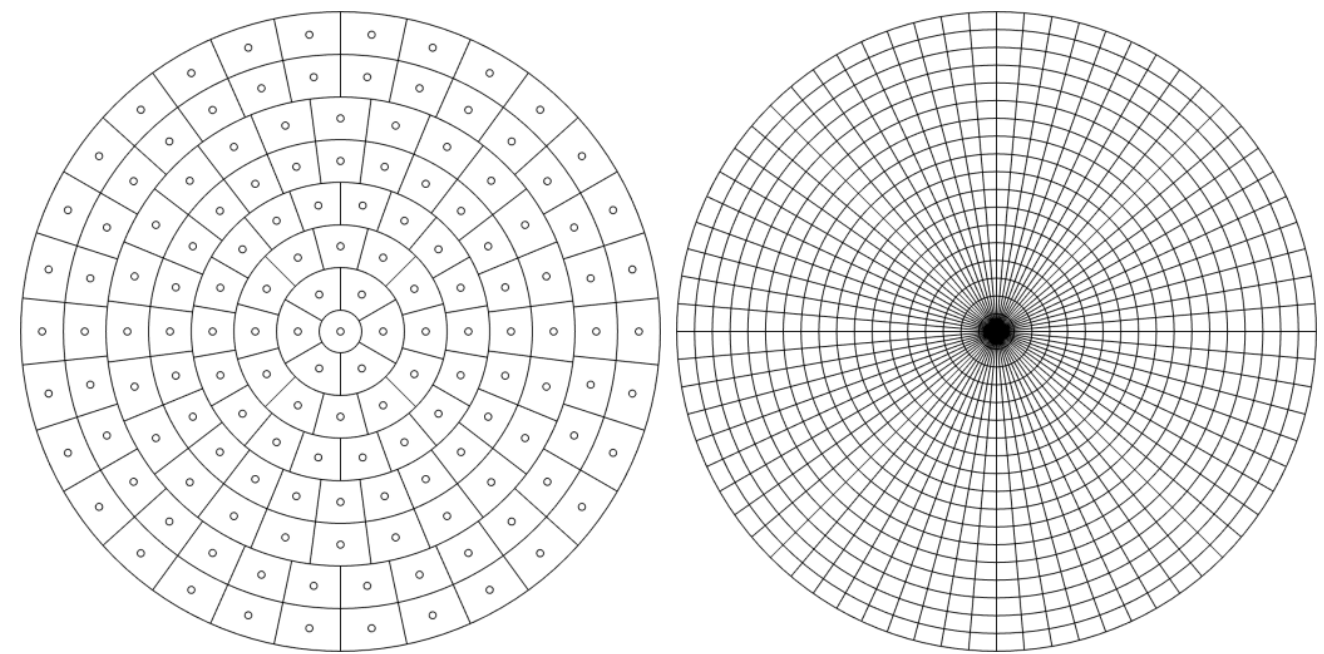

Figure 3. IEA21 BSDF angular basis [IEA 1999] for incident (left) and exiting (right) hemispheres.

\subsubsection{McNeil basis}

A modified version of the Klems basis was proposed in [McNeil et al., 2017] to provide a clear division between upward and downward flux for daylight-redirecting systems (Figure 4). This enables independent evaluation of the efficiency of redirection above the horizon (exiting flux in the upward direction at low grazing angles being most efficient for core daylighting) versus potential visual discomfort from downward transmitted flux below the horizon.

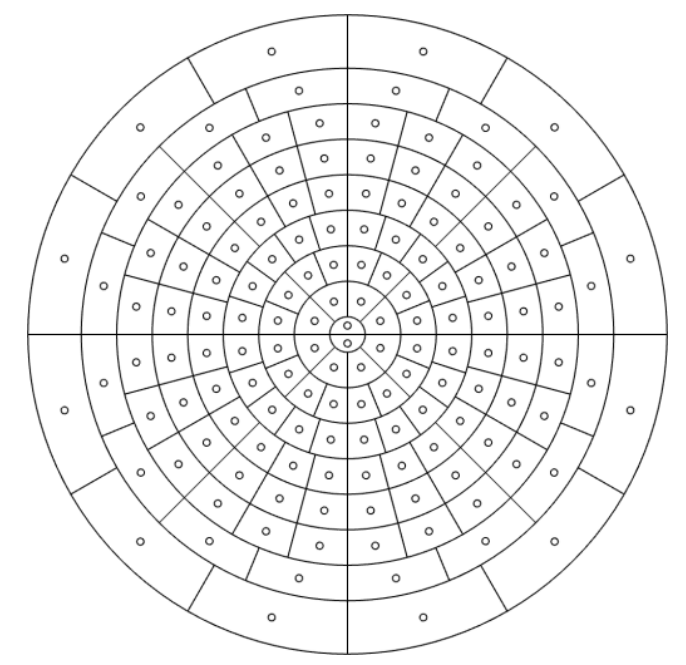

Figure 4. McNeil BSDF angular basis [McNeil et al. 2017] for incident / exiting hemispheres. 


\subsubsection{Shirley-Chiu, Tensor tree basis}

To enable a high-resolution representation of peaky areas in the exiting direction while keeping the overall data set reasonably small, [Ward et al., 2014] developed a variable-resolution BSDF representation (Figure 5). The general subdivision of the hemisphere is based on "a low distortion map between disk and square" [Shirley 1997], where neighboring areas with similar BSDF values (i.e., nearly diffuse behavior) are averaged to a single entry.
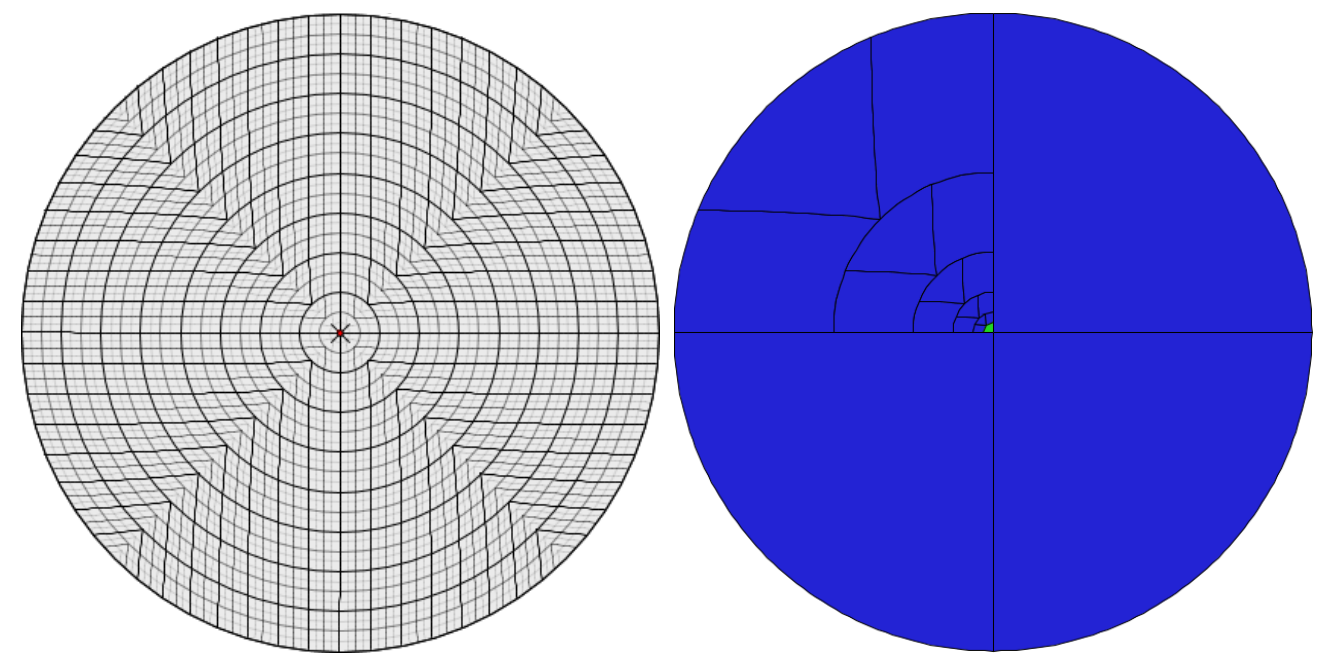

Figure 5. Example Shirley Chiu / Tensor tree angular basis [Ward et al., 2014] with basis resolution of 4096 patches, i.e., $2^{12}$ (left) and example exiting variable resolution hemisphere for specular glass (right).

\subsubsection{Overview}

The BSDFViewer software [McNeil 2013] can be used to display BSDF data in a falsecolor plot given either in Klems resolution or in Shirley-Chiu / Tensor tree resolution. Other possibilities to view BSDF data are provided e.g., by [Ladybug Tools 2020] and [LightTools 2020]. Table 1 summarizes current BSDF data formats and corresponding total number of subdivisions for the incident and exiting hemispheres.

Table 2 gives an overview of software tools currently available that can use BSDF data and which formats they support.

Table 1. Angular bases for tabulated BSDFs and number of subdivisions per incident and exiting hemispheres.

\begin{tabular}{|l|l|l|}
\hline BSDF angular basis & Incident hemisphere & Exiting hemisphere \\
\hline Klems & 145 (Klems) & 145 (Klems) \\
\hline IEA21 & 145 (Tregenza) & $1297\left(5^{\circ}\right.$ full, i.e., $\left.5^{\circ} \times 5^{\circ}\right)$ \\
\hline McNeil & 146 (Klems modified) & 146 (Klems modified) \\
\hline Shirley-Chiu, Tensor Tree & $\begin{array}{l}\text { variable basis resolution }=2^{2 n} \\
\text { (typical } n=4,5, \text { or } 6, \text { i.e., } 256, \\
1024, \text { or } 4096 \text { subdivisions) }\end{array}$ & $\begin{array}{l}\text { variable basis resolution }=2^{2 n} \\
\text { (typical } n=4,5, \text { or } 6, \text { i.e., } 256, \\
1024, \text { or 4096 subdivisions) }\end{array}$ \\
\hline
\end{tabular}


Table 2. Angular bases for tabulated BSDFs used by simulation software.

\begin{tabular}{|l|l|}
\hline BSDF angular basis & Software handling this basis (list not claiming to be exhaustive) \\
\hline Klems & $\begin{array}{l}\text { WINDOW, Radiance, Relux, Honeybee, DIVA4Rhino, Fener, DALEC, } \\
\text { LightStanza, COMFEN, IDA ICE, SPOT Pro, OpenStudio }\end{array}$ \\
\hline IEA21 & DIALux, Relux \\
\hline McNeil & $-{ }^{*}$ (Radiance with a modified genBSDF script [McNeil 2017]) \\
\hline $\begin{array}{l}\text { Shirley-Chiu, Tensor } \\
\text { Tree }\end{array}$ & Radiance, Honeybee, DIVA4Rhino, LightStanza \\
\hline
\end{tabular}

\subsection{BSDF file format}

Currently, [WINDOW 2020] enables generation of BSDF data with the Klems format. Within the Radiance BSDF library, the Klems and Shirley-Chiu / Tensor tree BSDF formats are supported and can be generated with the genBSDF tool. For alternate bases such as IEA21 or McNeil, Radiance's genBSDF program can be adapted to produce a tabulated BSDF file in these formats.

Note that conventions for phi and theta and the definition of front and back surfaces of the shading or daylighting system differ between goniophotometers, Radiance [Ward 2011, Radsite 2020b], and WINDOW [Curcija et al. 2018]). For anisotropic systems with different scattering properties between front and back surfaces (e.g., a daylight redirecting system with a clear zenith orientation and outdoor facing surface), ensuring that these conventions are clearly documented and aligned at each step when generating a BSDF is far more critical than for isotropic samples with the same properties on both sides of the system (e.g., translucent panel). The Radiance pabopto2bsdf script (see Section 5.2 Step 2) uses the convention suggested for a specific scanning goniophotometer [pab 2020]. When using genBSDF, the Radiance convention must be followed [Radsite 2020b]. Both bsdf2klems and bsdf2ttree convert from the Radiance convention to the WINDOW convention for the XML file, which is then converted back to the Radiance convention during rendering. 


\subsubsection{WINDOW XML file format}

We propose to follow the XML file format described in Section 6.4. of the WINDOW 6.1 / THERM 6.1 Research Version User Manual [Mitchell 2006]. This template specifies the "Layer" as a container holding three elements: "Material", "DataDefinition" and "WavelengthData".

As part of the "DataDefinition", the WINDOW specification for the Klems BSDF resolution is defined as "IncidentDataStructure" Columns and the "AngleBasis" with the "AngleBasisName" LBNL/Klems Full. Scattering data are provided in four $145 \times 145$ matrices for the four components: "Transmission Front", "Transmission Back", "Reflection Front" and "Reflection Back". With the WINDOW XML file format, the convention has been established that "front" is assumed to face outdoors, "back" indoors. The following designations are used:

\begin{tabular}{l|l|l}
\hline & Incident hemisphere & Exiting hemisphere \\
\hline Transmission front & Outdoors & Indoors \\
\hline Reflection front & Outdoors & Outdoors \\
\hline Transmission back & Indoors & Outdoors \\
\hline Reflection back & Indoors & Indoors \\
\hline
\end{tabular}

\subsubsection{Extensions available in Radiance}

To enable definition of high-resolution BSDF data in the XML scheme, [Ward 2011] extended the XML structure by adding the "IncidentDataStructure" types TensorTree3

for isotropic BSDF data and TensorTree4 for anisotropic BSDF data. The corresponding "AngleBasis" is defined as $L B N L /$ Shirley-Chiu. The scattering data is provided in nested lists with curly braces to specify the nodes of the tensor tree.

To include proxy geometry in the BSDF file, a further element "Geometry" has been defined. The current implementation in Radiance interprets geometry in the MGF format [Ward 1996] which is specified in the XML files as:

\section{<Geometry format="MGF" unit="meter"> \\ Geometry description in MGF format}

$</$ Geometry>

With this extension, proxy geometry can be included with the BSDF data set to enable improved calculations of the direct solar contribution (see Step 5 in Section 5.1).

Additional tags to the data will be needed to document the measurement conditions and analytical models from which the tabulated BSDF data were derived. This desired metadata is discussed in Section 7. 


\section{Proposed BSDF generation procedures}

We describe empirically-based procedures for generating BSDF data sets for façade systems for subsequent use in lighting simulation software. The overall procedure differs for microscopic and macroscopic systems. A simplified procedure for generating BSDFs for microscopic systems with rotational symmetry is also given.

For macroscopic systems, the procedure consists of four main steps and one optional step for including system geometry:

1. Characterize the base material using fundamental data (e.g., index of refraction, diffuse reflectance) or BSDF data generated for microscopic systems using the procedure above).

2. Set-up a three-dimensional geometric model of the window attachment; then,

3. Use simulations to produce a tabulated BSDF in the desired resolution using a virtual goniophotometer (optical ray-tracing software).

4. Validate the direct-hemispherical transmission values.

1. (optional): Prepare proxy geometry for inclusion in the BSDF XML file.

For microscopic systems, the procedure consists of four steps:

2. Take goniophotometer measurements of exiting transmittance and reflectance for selected incident directions.

3. Compute a four-dimensional interpolant from the measured data.

4. Sample the interpolant to derive a tabulated BSDF in the desired resolution.

5. Validate the direct-hemispherical transmission values.

For microscopic systems with rotational symmetry without highlights (e.g., isotropic fabrics, with or without a direct, through component (openness), but without light redirection) and for which the optical transmittance can be approximated by a specular/diffuse split, an alternate procedure is as follows:

1. Take integrating sphere measurements of normal-hemispherical and normal-diffuse transmittance and reflectance, and cut-off angle. Ensure that the angular range excluded from "normal-diffuse" is well-defined (see e.g., NFRC 300 or EN 14500:2020 [CEN 2020]).

2. Calculate normal-normal transmittance by subtracting the normal-diffuse transmittance from the normal-hemispherical transmittance.

3. Forge a Radiance BRTDfunc model as described in [Wienold et al. 2017]. This model takes as input parameters the normal-normal and normal-diffuse transmittance, the normalhemispherical reflectance, and the cut-off angle of the fabric.

4. Use simulations to produce a tabulated BSDF in the desired resolution using a virtual goniophotometer (optical ray-tracing software).

5. Validate the direct-hemispherical transmission values.

6. (optional): Use the BRTDfunc model as proxy geometry in the simulations. 


\subsection{BSDF generation procedure for macroscopic systems}

\subsubsection{Step 1: Characterization of the base material}

The material characterization is either provided by the manufacturer either as BRDF/BTDF data or as parameters for parametric models such as $\mathrm{ABg}$ or Gaussian, which e.g. are used in optical design software. For refractive systems, the index of refraction, absorption coefficients, and parameters for volume scattering (if relevant) are provided.

If the necessary data or analytical model parameters are not provided by the manufacturer, the material properties are measured using a goniophotometer following the BSDF generation procedure for microscopic systems (see Section 5.2). The resulting data are either fitted to parametric models (Section 5.2, Steps 1 and 2) or converted into a tabulated BSDF (Section 5.2, Steps 1 to 3) for further use in simulation tools.

\subsubsection{Step 2: Set-up of a 3D geometry model of the window attachment}

A three-dimensional (3D) geometrical model of the window attachment needs to be prepared in a computer-aided design (CAD) system for import into lighting simulation software. The geometric model must encompass a large area of the system so that a representative area of the system in the center of the CAD model can be extracted. One should define an area where the rays are spawned, and this area should encompass an integer number of periodic features of the system. Taking venetian blinds as an example, a periodic feature would be a blind and a gap. This area should also be small enough compared to the entire system geometry. In this way, edge effects can be avoided and a generic BSDF for the system can be generated. General limitations and restrictions of geometrical models are discussed later in Section 0.

\subsubsection{Step 3: Simulation of a tabulated BSDF in the desired resolution using a virtual goniophotometer (optical software).}

The material model (analytical or tabulated BSDF) from Step 1 is applied in the simulation software to the 3D geometry prepared in Step 2. Using optical simulation software, the BSDF of the system is then generated by mimicking a goniophotometer setup (infinite plane of material). For the desired resolution of the final BSDF, all incident-to-exiting patch relations are evaluated. A uniform light distribution over each single patch of incident directions is used to illuminate the sample and the resulting exiting distribution is evaluated through integration over the single exiting patch directions.

The Radiance software includes a virtual goniophotometer tool called genBSDF. This utility can be used to generate BSDF data of virtual 3D models in low resolution (Klems basis) and in high resolution (tensor tree with variable resolution). Validation of genBSDF was completed by [McNeil et al. 2013].

\subsubsection{Step 4: Validation of direct-hemispherical transmission values}

As for microscopic systems (compare Step 4 in Section 5.2) also for macroscopic systems the directhemispherical transmission values are validated through integrating sphere measurements. Therefore, the illuminated area and transmittance sample aperture must have linear dimensions that are several times larger (at least a factor of five, or better ten) than the linear dimensions of inhomogeneity. This ensures that the geometric modelling and simulation adequately represent the properties of the system in terms of overall transmitted light flux. Again, to have a valid BSDF, the relative difference of

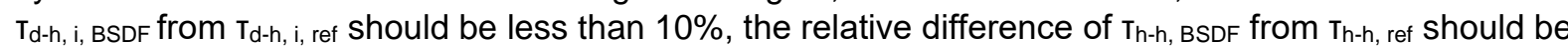
no more than $5 \%$. 


\subsubsection{Step 5 (optional): Preparation of proxy geometry for inclusion in BSDF XML file}

As described in Section 4.2, geometry information of the daylight system can be included in the BSDF XML file. The geometry can be used in simulations as a proxy for the BSDF description of the daylight system in the shadow testing algorithm. As an example, for venetian blinds, this enables the rendering of shadow patterns instead of an averaged, extenuated light patch inside the room. With this, the direct solar contribution to interior light levels can be calculated with greater accuracy. Additionally, proxy geometry provides a correct appearance of the system in the facade.

The provision of exact system geometry could be prohibited because of intellectual property (IP) protections. Thus, it might be useful to adapt or simplify the geometry in a way that the resulting proxy does not disclose protected knowledge, while still producing approximately correct shadow patterns and appearance.

\subsection{BSDF generation procedure for microscopic systems}

\subsubsection{Step 1: Goniophotometer measurements}

In the first step, measurements are taken of a flat sample with a goniophotometer for selected incident directions. Depending on the symmetry of the sample, 9, 45, 81 or 145 incident directions (assuming the Klems basis) may need to be measured for systems with rotational, quadrilateral, bilateral, or no symmetry, respectively. Table 3 lists the $\theta$ and $\varphi$ angles associated with these incident directions. Measurement of a subset of these incident directions may be sufficient, resulting in a minimal loss of accuracy. However, further sensitivity analysis is needed to understand the effects on error for each system. An example sensitivity analysis is given in [Lee et al. 2018]. Further discussion on measurement directions and limitations can be found in Section 7.4.

In the exiting directions, measurement requirements for angular resolution depends on the type of shading or daylighting material. For materials that do not exhibit specular or semi-specular transmission or reflection, for example, high-resolution angular measurements in the exiting hemisphere may not be necessary. For materials that do exhibit specular or peaky distributions with transmission or reflection, high resolution measurements are needed. For the latter, the goniophotometer must be able to take high angular resolution measurements to capture the shape of the peaks and be accurate within a broad dynamic range (e.g., angular resolution of better than $0.04^{\circ}$, step size of $0.01^{\circ}$, and contrast of greater than 1:20,000 [Schwanengel 2010]).

BSDF system characterizations and goniophotometer measurements are undertaken at various institutions worldwide. Within the IEA SHC Task 61 / EBC Annex 77 "Integrated Solutions for Daylighting and Electric Lighting", international experts reviewed and documented currently used measurement methods [IEA 2020] (Figure 6). In [IEA, 1999] prior measurement methods are described. These procedures have been co-developed and vetted amongst a handful of institutions under prior IEA Tasks 21 and 50 and related research projects (e.g., BIM-SOL [Grobe 2018a]). A discussion on broadening industry's measurement capabilities is given in Section 7. 
Table 3. Proposed incident directions for goniophotometric measurements.

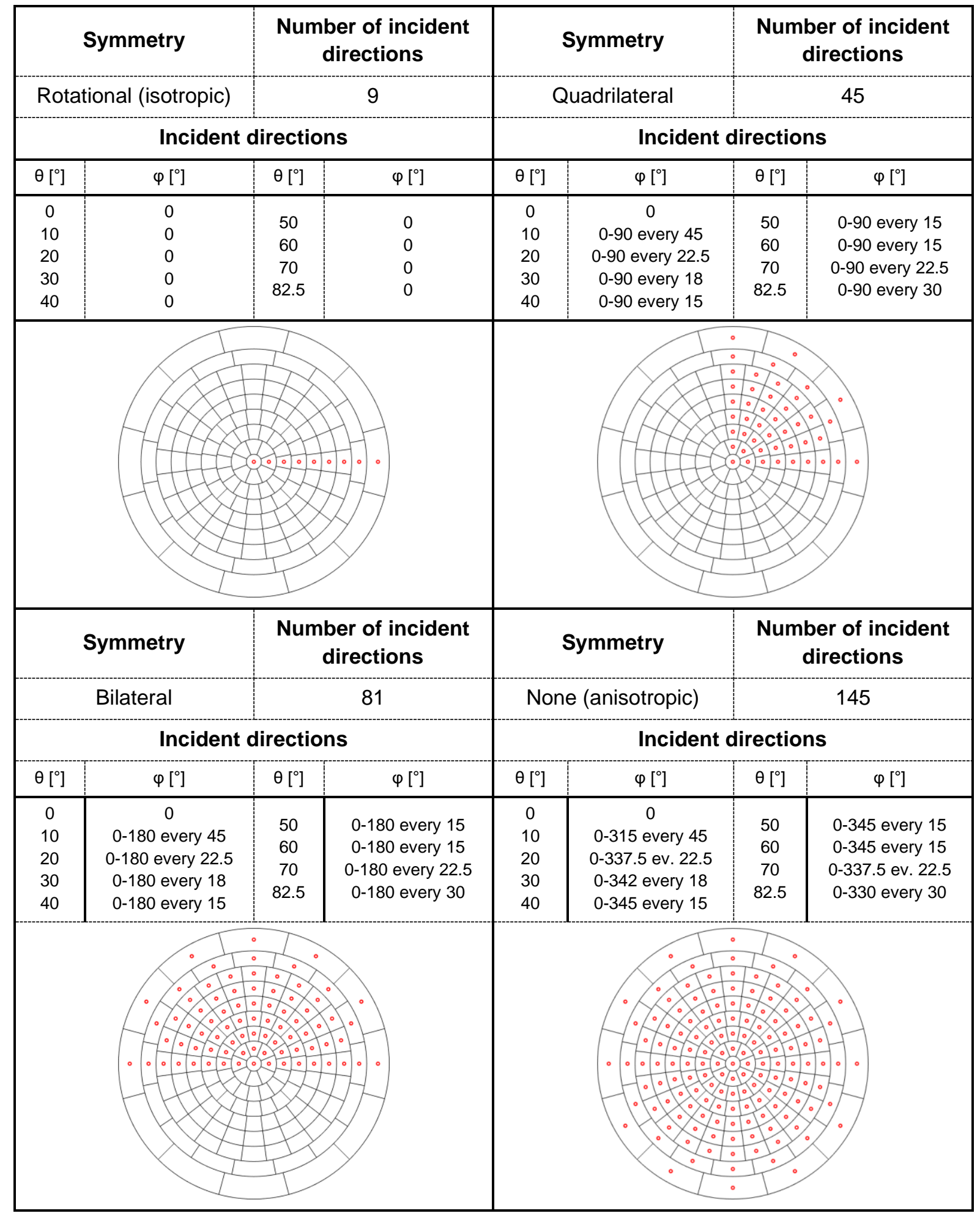



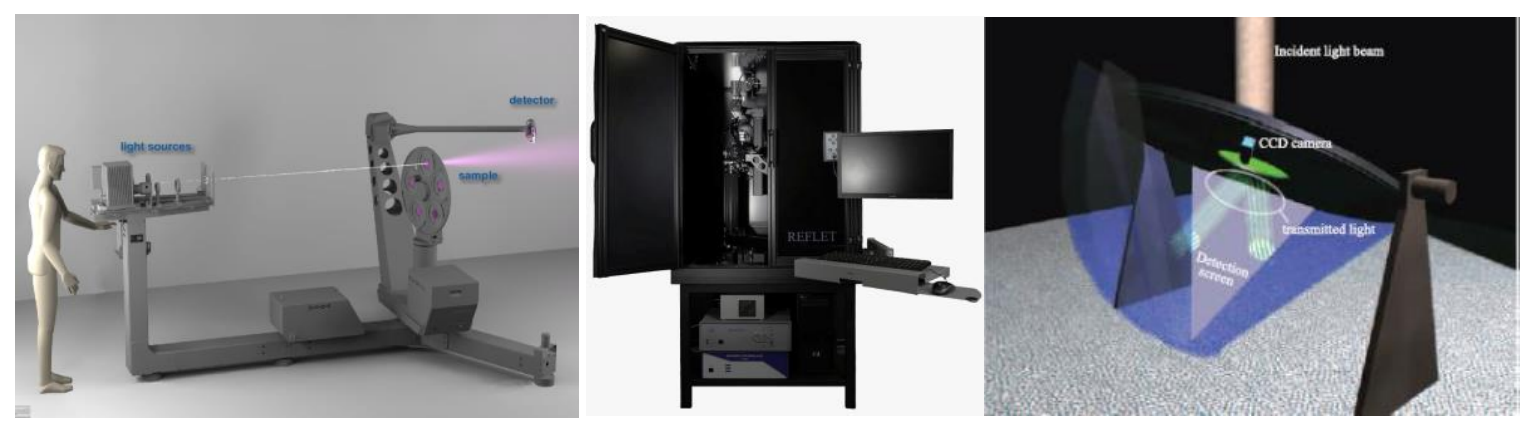

Figure 6. Examples of goniophotometer measurement setups: left: pab Ltd Gonio-Photometer II; center: Lighttec Reflet 180S; right: LESO-PB / EPFL video-goniophotometer. Sources: [pab 2020], [Light Tec 2020], [Andersen 2005].

\subsubsection{Step 2: Fitting a four-dimensional interpolant}

For the selected incident directions in Step 1, we have a point cloud of data in the exiting direction with corresponding BSDF values. For further use in simulations, a full four-dimensional description of the BSDF is required. This can be achieved by fitting parameters of an analytical scattering model to the data (e.g., the Ashikhmin-Shirley model or the Ward-Geisler-Moroder-Dür model, see Section 2). This however limits the possible shapes to the scope of the models and often yields faulty results.

For this step, the proposed method is to generate an interpolant model for the measured incident directions based on a fit to the measured exiting distribution using Gaussian radial basis functions (RBF) [Ward 2014]. In the Radiance BSDF library, this fitting is done by the tool pabopto2bsdf [Radsite 2020a]. This model is still sparse on the incident hemisphere, but includes information needed to interpolate properly in all four dimensions.

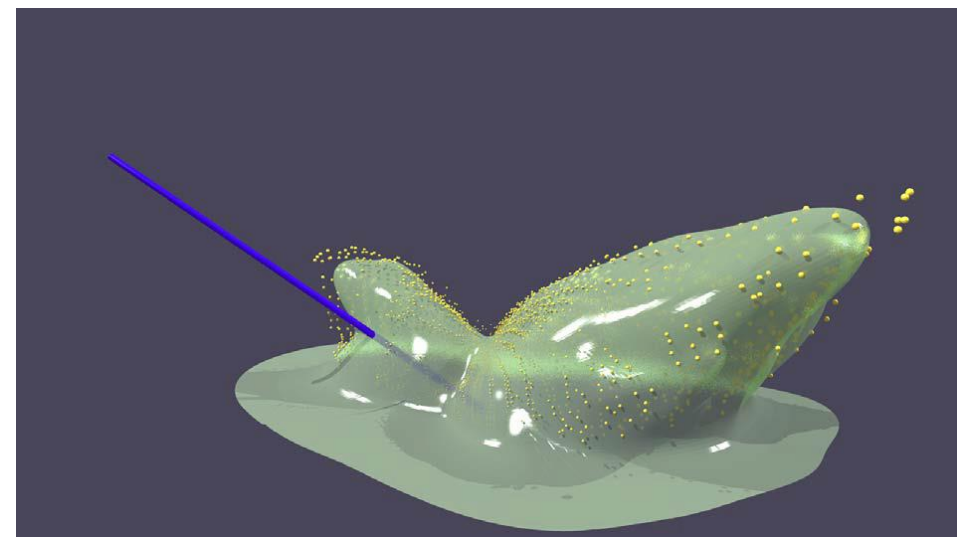

Figure 7. Fitting of an interpolant RBF model (green) to a set of measured values (yellow points), log scale. Source: G. Ward [Lee 2018]. 


\subsubsection{Step 3: Sampling the interpolant model to derive a tabulated BSDF in the desired resolution}

The Gaussian RBF model from Step 2 is then transformed into the desired resolution of a tabulated BSDF. To obtain a full hemispherical distribution, the incident directions must be interpolated. To avoid erroneous peak positions through linear interpolation, a mass transport algorithm must also be applied.

Integrating the RBF model over the related solid angle areas using Monte Carlo methods, the particular incident-to-exiting patch relations are obtained. This method is also applied in the relevant tools in the Radiance BSDF library. bsdf2klems generates low-resolution BSDF data sets based on the Klems angular basis, while bsdf2ttree is used to convert the BSDF into a variable-resolution data set based on tensor trees [Ward et al. 2014].

If the BSDF data of the microscopic system is later used for a simulation-based generation of BSDF data for a macroscopic system (Step 1 in Section 5.1), care must be taken to choose a resolution that covers the material's relevant properties. If e.g., a Klems resolution is used to represent a high specular aluminum material, no reasonable high-resolution tensor tree BSDF of a blind system made of this material can be generated. The low-resolution base material would already misrepresent any reflection off the slat.

\subsubsection{Step 4: Validation of direct-hemispherical transmission values}

Direct-hemispherical transmission and reflectance values are measured using a nearly parallel light beam (e.g., sunlight outdoors or indoors via redirecting mirrors or an artificial light beam ("artificial sun")) and an integrating sphere. To capture relevant structures in the resulting distributions, a resolution of at least $5^{\circ}$ for both polar and azimuthal angles is proposed for the incident directions, preferably a resolution of $1^{\circ}$ is used. Bilinear interpolation is used to generate a full hemispherical distribution. Multiple measurements of different areas of the sample can be made to characterize errors associated with variability in manufacturing.

The resulting distribution from the integrating sphere is integrated over the incident patch areas of the generated BSDF to obtain an average direct-hemispherical transmission $T_{d}-h, i$, ref for each incident

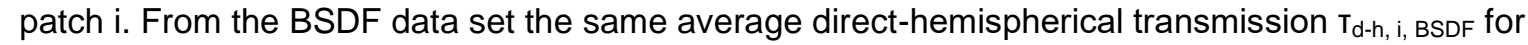
each incident patch $\mathrm{i}$ is calculated by integration over the exiting distribution in the BSDF.

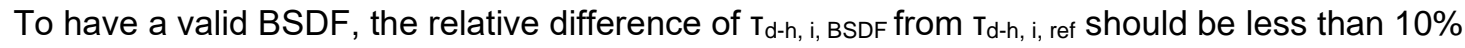
(referring to error limits of DIN class B luxmeters [DIN 2017, Gossen 2019] and findings from [IEA 1999]).

The hemispherical-hemispherical transmission values $\mathrm{Th}_{\mathrm{h}}$, ref and $\mathrm{T}_{\mathrm{h}} \mathrm{h}, \mathrm{BSDF}$, are derived through

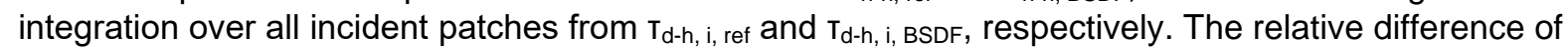
$T_{h-h, ~ B S D F}$ from $T_{h-h,}$ ref should be no more than $5 \%$.

\subsection{BSDF generation procedure for microscopic systems: Simplified method for isotropic, non-reflective materials}

\subsubsection{Step 1: Integrating sphere measurements}

The following brief set of best practices for integrating sphere measurements are based on research work in preparation for the revised version of EN 14500, which should come into effect in 2020 [CEN 2020]. In multi-purpose integrating spheres intended for use together with high-end laboratory benchtop spectrophotometers, it is important that the internal surface of the integrating sphere be as homogeneous as possible, i.e. the ratio of sample and detector aperture areas should be small $(<0.1)$ compared to the total sphere area and the white material used as reflection references and to close apertures should be similar in scattering distribution and spectrum to the white material coating the sphere interior. 
As it is widespread practice to measure normal-diffuse transmittance or reflectance by opening an aperture to allow the normal-normal component to exit the sphere, it is important to specify the effective solid angle which this aperture represents within the sphere. EN 14500 restricts the ratio of aperture area to internal sphere area to between 0.0035 and $\leq 0.007$. This ratio directly determines the ratio of the normal-normal to normal-diffuse components, that is central to the following steps. The sample should not be moved between making the normal-hemispherical and normal-diffuse measurements, as they are used to calculate the corresponding normal-normal quantity.

Even for conventional, woven fabrics, the cut-off angle may vary considerably, depending on the azimuthal angle of the incident radiation with respect to the warp or the weft threads, so this azimuthal angle should be specified unambiguously together with the determined cut-off angle. The divergence of the illuminating beam should be as small as possible and the beam cross-section small with respect to the distance to the detector, so that the origin of the subtended angle between the sample normal and detector is well-defined. To distinguish between angles larger and smaller than the cut-off angle, it is essential that the detector be sensitive to low light levels and that stray light is excluded from the measurement.

\subsubsection{Step 2: Calculate normal-normal transmittance}

The normal-normal transmittance $\left(T_{n-n}\right)$ can be determined from the normal-hemispherical transmittance $\left(T_{n-h}\right)$ and the normal-diffuse transmittance $\left(T_{n-\text { dif }}\right)$, viz. $T_{n-n}=T_{n-h}-T_{n-d i f}$.

\subsubsection{Step 3: Create a Radiance BRTDfunc model}

The normal-normal transmittance, normal-diffuse transmittance, normal-hemispherical reflectance, and cut-off angle of the material is used to create a Radiance BRTDfunc model [Wienold et al. 2017]. The BRTDfunc model assumes rotational symmetry, i.e., isotropic behavior. $\mathrm{T}_{\mathrm{n}-\mathrm{n}}$ energy (measured for the integrating sphere $5^{\circ}$ cone) is assigned to a $0.5^{\circ}$ cone (sun orb) with purely specular transmission in the exiting direction. Angular fall-off in direct-direct transmission with increasing theta angle is based on a modified version of the Roos model for clear glass [Roos et al. 2001]. EN 14500 [CEN 2020] suggests defining the cut off angle by $T_{\text {dir-dir }}<0.005$ from the fall-off function, where $T_{\text {dir-dir }}=0$ for theta angles greater than the cut off angle. Angular fall-off in Tdir-h follows a similar relationship to that of Tdir-dir and assumes a Lambertian distribution in the exiting direction. Transmission properties of actual fabrics may diverge significantly from this simplified model. On the other hand, this approach makes sure that the direct-direct transmittance is treated as purely specular and that the total transmission value is at least correct for the normal incident angle.

\subsubsection{Step 4: Simulation of a tabulated BSDF in the desired resolution using a virtual goniophotometer (optical software)}

The material model from Step 3 is applied in the virtual goniophotometer from Radiance, a tool called genBSDF. This utility can be used to generate BSDF data of virtual 3D models in low resolution (Klems basis) and in high resolution (tensor tree with variable resolution). Validation of genBSDF was completed by [McNeil et al. 2013].

\subsubsection{Step 5: Validation of direct-hemispherical transmission values}

The resulting BSDF from Step 4 are integrated to obtain direct-hemispherical properties, which are compared with the initial measured values from the integrating sphere. This ensures that the geometric modelling and simulation adequately represent the properties of the system in terms of overall transmitted light flux.

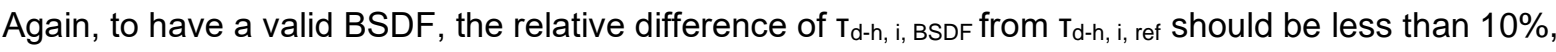
the relative difference of $T_{h-h}, B S D F$ from $T_{h-h}$, ref should be no more than $5 \%$. 


\subsubsection{Step 6 (optional): Use the BRTDfunc model as proxy geometry in the simulations}

The BRTDfunc model developed in Step 2 can directly be used, e.g. to calculate simplified images for the Enhanced Simplified DGP method in annual glare risk assessments. This ensures that the directdirect transmittance is treated purely specular in the simulations. More details are given in the Discussion Section 7.8. As described in Section 4.2, the proxy model of the daylight system can be included in the BSDF XML file.

\section{Proposed characterization types for various kinds of daylight systems}

As stated in Section 0, different systems require different BSDF data resolutions for different applications. Based on several studies [McNeil 2011, Geisler-Moroder et al. 2017, Kurt 2018, GeislerMoroder 2019, Pedersen and Rasmussen 2019], the following tables recommend characterization methods and BSDF resolutions for different classes of systems. The classes of systems are clustered according to their optical properties and the resulting requirements for data resolutions.

For selected metrics, some system types are best modelled using an analytical or material model (e.g., clear glazing via a single transmittance value without any scattering) or even using a geometric model of the system with an appropriate base material (e.g., diffuse venetian blinds), as described in Section 5.1. This however presumes that either an adequate analytical model or the system geometry is available.

The "peak extraction" algorithm, which is for example implemented in Radiance, enables modelling of peaks in the unscattered direct-through direction of a tabulated BSDF. For systems with a strong specular transmission component such as clear windows, venetian blinds (direct transmission between slats) or perforated fabrics (with a relevant openness factor), this algorithm enables calculation of the direct solar contribution to the interior light levels based on a transmission value estimated from the directional BSDF value. This is also assumed to be the most critical peak appearance for the investigated performance metrics, especially for glare evaluations. However, if offspecular and upward-reflected peaks are expected, the method of photon mapping with highresolution BSDFs [Grobe 2019] is recommended.

As another option for detailed calculations of the direct solar component, proxy geometry can be useful in various simulation methods. The pros and cons of having proxy geometry available are given in Step 5 in Section 5.1.

In the tables, the "example simulation methods" (middle column of the tables) provide working examples but makes no claim to be complete. The "proposed system characterization" (right column) or BSDF resolution applies to the overall system, not to the base material. 


\subsection{Transparent systems}

Systems of this class only transmit light in the direct-through direction (specular transmission) and reflect light in the mirror direction (specular reflection) of the incident light. They do not scatter light in any other direction. Systems can be described with an analytical model for the material, which can then be used with the geometry of the window. The analytical model can also be used to generate low- or high-resolution BSDFs (e.g., for use in matrix-based methods and for cases with switchable glass or operable, variable-height shades).

Example facade systems:

- clear glazing

- electrochromic glazing

- clear films

\begin{tabular}{|c|c|c|}
\hline $\begin{array}{l}\text { Daylighting Performance } \\
\text { Metric }\end{array}$ & $\begin{array}{l}\text { Example simulation } \\
\text { method }\end{array}$ & $\begin{array}{l}\text { Proposed system } \\
\text { characterization (model or BSDF } \\
\text { resolution) }\end{array}$ \\
\hline Daylight Factor & $\begin{array}{l}\text { Raytracing with } \\
\text { continuous sky model }\end{array}$ & Geometry with material description \\
\hline $\begin{array}{l}\text { Point-in-time illuminance for } \\
\text { overcast / sunny sky }\end{array}$ & $\begin{array}{l}\text { Raytracing with } \\
\text { continuous sky model }\end{array}$ & Geometry with material description \\
\hline $\begin{array}{l}\text { Point-in-time glare metric for } \\
\text { overcast / sunny sky }\end{array}$ & $\begin{array}{l}\text { Raytracing with } \\
\text { continuous sky model }\end{array}$ & Geometry with material description \\
\hline $\begin{array}{l}\text { Point-in-time rendering for } \\
\text { overcast / sunny sky }\end{array}$ & $\begin{array}{l}\text { Raytracing with } \\
\text { continuous sky model }\end{array}$ & Geometry with material description \\
\hline $\begin{array}{l}\text { Annual illuminance/energy } \\
\text { metric }\end{array}$ & DC method or 3PM & $\begin{array}{l}\text { Geometry with material description } \\
\text { or low-resolution BSDF }\end{array}$ \\
\hline \multirow[b]{2}{*}{ Annual glare metric } & Raytracing, or & $\begin{array}{l}\text { Geometry with material description, } \\
\text { or }\end{array}$ \\
\hline & $\begin{array}{l}\text { 5PM; } \\
\text { BSDF peak extraction }\end{array}$ & $\begin{array}{l}\text { Low-resolution BSDF for 3PM part } \\
\text { and } \\
\text { i. geometry with material } \\
\text { description or } \\
\text { ii. high-resolution BSDF or } \\
\text { iii. low-resolution BSDF (if peak } \\
\quad \text { extraction in method) } \\
\text { for accurate direct contribution }\end{array}$ \\
\hline
\end{tabular}




\subsection{Homogeneous or small pattern diffusing systems}

Systems of this class scatter light both in transmission and reflection. They may also have an additional specular transmission and/or specular reflection component. For the observer, they have a homogeneous appearance. Procedures described under Section 5.2 are typically used to characterize these systems.

Example facade systems:

- roller shades

- fritted glass

- translucent panels

- diffusion filters

- small scale expanded metal mesh

- ETFE films

\begin{tabular}{|c|c|c|}
\hline $\begin{array}{l}\text { Daylighting Performance } \\
\text { Metric }\end{array}$ & $\begin{array}{l}\text { Example simulation } \\
\text { method }\end{array}$ & $\begin{array}{l}\text { Proposed system } \\
\text { characterization (model or } \\
\text { BSDF resolution) }\end{array}$ \\
\hline Daylight Factor & $\begin{array}{l}\text { Raytracing with } \\
\text { continuous sky model }\end{array}$ & Low-resolution BSDF \\
\hline $\begin{array}{l}\text { Point-in-time illuminance for } \\
\text { overcast / sunny sky }\end{array}$ & $\begin{array}{l}\text { Raytracing with } \\
\text { continuous sky model }\end{array}$ & Low-resolution BSDF \\
\hline $\begin{array}{l}\text { Point-in-time glare metric for } \\
\text { overcast / sunny sky }\end{array}$ & $\begin{array}{l}\text { Raytracing with } \\
\text { continuous sky model; } \\
\text { BSDF peak extraction }\end{array}$ & $\begin{array}{l}\text { High-resolution BSDF or } \\
\text { Low-resolution BSDF with peak } \\
\text { extraction }\end{array}$ \\
\hline $\begin{array}{l}\text { Point-in-time rendering for } \\
\text { overcast / sunny sky }\end{array}$ & $\begin{array}{l}\text { Raytracing with } \\
\text { continuous sky model } \\
\text { BSDF peak extraction }\end{array}$ & $\begin{array}{l}\text { High-resolution BSDF or } \\
\text { Low-resolution BSDF with peak } \\
\text { extraction }\end{array}$ \\
\hline $\begin{array}{l}\text { Annual illuminance/energy } \\
\text { metric }\end{array}$ & $\begin{array}{l}\text { DC-method (for static } \\
\text { systems) or 3PM }\end{array}$ & Low-resolution BSDF \\
\hline \multirow[b]{2}{*}{ Annual glare metric } & Raytracing, or & $\begin{array}{l}\text { Low-resolution BSDF with peak } \\
\text { extraction }\end{array}$ \\
\hline & $\begin{array}{l}\text { 5PM; } \\
\text { BSDF peak extraction }\end{array}$ & $\begin{array}{l}\text { Low-resolution BSDF for 3PM part } \\
\text { and } \\
\text { i. High-resolution BSDF or } \\
\text { ii. Low-resolution BSDF with } \\
\text { for accurate direct contribution }\end{array}$ \\
\hline
\end{tabular}




\subsection{Diffuse blinds or grids}

Systems of this class reflect light off their opaque elements (slats) mainly diffusely or scattered. They have a distinct specular transmission component through openings between the elements, with usually high angular dependency based on the geometry. Procedures described for macroscopic systems (Section 5.1) are typically used to characterize these systems.

Example facade systems:

- venetian blinds

- roller shutters

- large scale metal mesh

\begin{tabular}{|c|c|c|}
\hline $\begin{array}{l}\text { Daylighting Performance } \\
\text { Metric }\end{array}$ & $\begin{array}{l}\text { Example simulation } \\
\text { method }\end{array}$ & $\begin{array}{l}\text { Proposed system } \\
\text { characterization (model or BSDF } \\
\text { resolution) }\end{array}$ \\
\hline Daylight Factor & $\begin{array}{l}\text { Raytracing with continuous } \\
\text { sky model, possibly } \\
\text { mkillum }\end{array}$ & $\begin{array}{l}\text { Geometry or } \\
\text { Low-resolution BSDF }\end{array}$ \\
\hline $\begin{array}{l}\text { Point-in-time illuminance for } \\
\text { overcast / sunny sky }\end{array}$ & $\begin{array}{l}\text { Raytracing with continuous } \\
\text { sky model }\end{array}$ & $\begin{array}{l}\text { Geometry or } \\
\text { Low-resolution BSDF }\end{array}$ \\
\hline $\begin{array}{l}\text { Point-in-time glare metric for } \\
\text { overcast / sunny sky }\end{array}$ & $\begin{array}{l}\text { Raytracing with continuous } \\
\text { sky model; BSDF peak } \\
\text { extraction }\end{array}$ & $\begin{array}{l}\text { High-resolution BSDF or } \\
\text { Low-resolution BSDF (with peak } \\
\text { extraction) }\end{array}$ \\
\hline $\begin{array}{l}\text { Point-in-time rendering for } \\
\text { overcast / sunny sky }\end{array}$ & $\begin{array}{l}\text { Raytracing with continuous } \\
\text { sky model; BSDF peak } \\
\text { extraction }\end{array}$ & $\begin{array}{l}\text { High-resolution BSDF or } \\
\text { Low-resolution BSDF if peak } \\
\text { extraction }\end{array}$ \\
\hline $\begin{array}{l}\text { Annual illuminance/energy } \\
\text { metric }\end{array}$ & $\begin{array}{l}\text { DC-method (static } \\
\text { systems) or 3PM }\end{array}$ & Low-resolution BSDF \\
\hline Annual glare metric & $\begin{array}{l}\text { 5PM; } \\
\text { BSDF peak extraction }\end{array}$ & $\begin{array}{l}\text { Low-resolution BSDF for 3PM part } \\
\text { and } \\
\text { i. Low-resolution BSDF with } \\
\text { ii. Heometry or } \\
\text { iii. Low-resolution BSDF only } \\
\text { if peak extraction } \\
\text { for accurate direct contribution }\end{array}$ \\
\hline
\end{tabular}




\subsection{Specular blinds or grids}

Systems of this class reflect light off their elements or geometry in mainly a specular manner. They have a distinct specular transmission component through openings between the elements, with usually high angular dependency based on the geometry. Procedures described for macroscopic systems (Section 5.1) are typically used to characterize these systems.

Example facade systems:

- specular venetian blinds

- large scale metal mesh with specular finish

\begin{tabular}{|l|l|l|}
\hline $\begin{array}{l}\text { Daylighting Performance } \\
\text { Metric }\end{array}$ & $\begin{array}{l}\text { Example simulation } \\
\text { method }\end{array}$ & $\begin{array}{l}\text { Proposed system } \\
\text { characterization (model or BSDF } \\
\text { resolution) }\end{array}$ \\
\hline Daylight Factor & $\begin{array}{l}\text { Raytracing with continuous } \\
\text { sky model; possibly } \\
\text { mkillum }\end{array}$ & $\begin{array}{l}\text { Geometry or } \\
\text { Low-resolution BSDF }\end{array}$ \\
\hline $\begin{array}{l}\text { Point-in-time illuminance for } \\
\text { overcast / sunny sky }\end{array}$ & $\begin{array}{l}\text { Raytracing with continuous } \\
\text { sky model; } \\
\text { BSDF peak extraction }\end{array}$ & Low-resolution BSDF \\
\hline $\begin{array}{l}\text { Point-in-time glare metric for } \\
\text { overcast / sunny sky }\end{array}$ & $\begin{array}{l}\text { Raytracing with continuous } \\
\text { sky model; BSDF peak } \\
\text { extraction (specular } \\
\text { transmission); photon } \\
\text { mapping (specular } \\
\text { transmission and } \\
\text { reflection) }\end{array}$ & High-resolution BSDF \\
\hline $\begin{array}{l}\text { Point-in-time rendering for } \\
\text { overcast / sunny sky }\end{array}$ & $\begin{array}{l}\text { Raytracing with continuous } \\
\text { sky model; BSDF peak } \\
\text { extraction }\end{array}$ & $\begin{array}{l}\text { (a) High-resolution BSDF or } \\
\text { (b) Low-resolution BSDF with peak } \\
\text { extraction }\end{array}$ \\
\hline Annual illuminance metric & DC-method or 3PM & Low-resolution BSDF \\
\hline Annual glare metric & $\begin{array}{l}\text { 5PM; } \\
\text { BSDF peak extraction }\end{array}$ & $\begin{array}{l}\text { Low-resolution BSDF for 3PM part } \\
\text { and high-resolution BSDF for } \\
\text { accurate direct contribution }\end{array}$ \\
\hline
\end{tabular}




\subsection{Macroscopic prismatic systems}

Systems of this class typically redirect the incident light beam in the transmitted and/or reflected directions, with or without scattering. They usually show pronounced peaks in off-specular or off-mirror directions. Procedures described for macroscopic systems (Section 5.1) are typically used to characterize these systems.

Example facade systems:

- sun protection prisms

- laser cut panels

\begin{tabular}{|l|l|l|}
\hline Metric & $\begin{array}{l}\text { Proposed simulation } \\
\text { method }\end{array}$ & $\begin{array}{l}\text { Proposed system } \\
\text { characterization (model or BSDF } \\
\text { resolution) }\end{array}$ \\
\hline Daylight Factor & $\begin{array}{l}\text { Raytracing with continuous } \\
\text { sky model }\end{array}$ & Low-resolution BSDF \\
\hline $\begin{array}{l}\text { Point-in-time illuminance for } \\
\text { overcast / sunny sky }\end{array}$ & $\begin{array}{l}\text { Raytracing with continuous } \\
\text { sky model; } \\
\text { BSDF peak extraction }\end{array}$ & Low-resolution BSDF \\
\hline $\begin{array}{l}\text { Point-in-time glare metric for } \\
\text { overcast / sunny sky }\end{array}$ & $\begin{array}{l}\text { Raytracing with continuous } \\
\text { sky model; BSDF peak } \\
\text { extraction (specular } \\
\text { transmission); photon } \\
\text { mapping (specular } \\
\text { transmission and } \\
\text { reflection) }\end{array}$ & High-resolution BSDF \\
\hline $\begin{array}{l}\text { Point-in-time rendering for } \\
\text { overcast / sunny sky }\end{array}$ & $\begin{array}{l}\text { Raytracing with continuous } \\
\text { sky model; } \\
\text { BSDF peak extraction }\end{array}$ & High-resolution BSDF \\
\hline Annual illuminance metric & 3PM & \begin{tabular}{l} 
Low-resolution BSDF \\
\hline Annual glare metric
\end{tabular} \\
\hline $\begin{array}{l}\text { 5PM; } \\
\text { BSDF peak extraction }\end{array}$ & $\begin{array}{l}\text { Low-resolution BSDF for 3PM part } \\
\text { and high-resolution BSDF for } \\
\text { accurate direct contribution }\end{array}$ \\
\hline
\end{tabular}




\subsection{Micro-/Nano-structured systems}

Systems of this class scatter light both in transmission and reflection. They may also have an additional specular transmission and/or specular reflection component as well as pronounced peaks in off-specular and off-mirror directions. For the observer they give a homogeneous appearance. Procedures described for microscopic systems (Section 5.2) are typically used to characterize these systems.

Example facade systems:

- microprismatic films

- holographic optical elements

\begin{tabular}{|l|l|l|}
\hline $\begin{array}{l}\text { Daylighting Performance } \\
\text { Metric }\end{array}$ & $\begin{array}{l}\text { Example simulation } \\
\text { method }\end{array}$ & $\begin{array}{l}\text { Proposed system } \\
\text { characterization (model or BSDF } \\
\text { resolution) }\end{array}$ \\
\hline Daylight Factor & $\begin{array}{l}\text { Raytracing with continuous } \\
\text { sky model }\end{array}$ & Low-resolution BSDF \\
\hline $\begin{array}{l}\text { Point-in-time illuminance for } \\
\text { overcast / sunny sky }\end{array}$ & $\begin{array}{l}\text { Raytracing with continuous } \\
\text { sky model; } \\
\text { BSDF peak extraction }\end{array}$ & Low-resolution BSDF \\
\hline $\begin{array}{l}\text { Point-in-time glare metric for } \\
\text { overcast / sunny sky }\end{array}$ & $\begin{array}{l}\text { Raytracing with continuous } \\
\text { sky model; BSDF peak } \\
\text { extraction (specular } \\
\text { transmission); Photon } \\
\text { mapping (specular } \\
\text { transmission and } \\
\text { reflection) }\end{array}$ & High-resolution BSDF \\
\hline $\begin{array}{l}\text { Point-in-time rendering for } \\
\text { overcast / sunny sky }\end{array}$ & $\begin{array}{l}\text { Raytracing with continuous } \\
\text { sky model; } \\
\text { BSDF peak extraction }\end{array}$ & High-resolution BSDF \\
\hline Annual illuminance metric & 3PM & Low-resolution BSDF \\
\hline Annual glare metric & $\begin{array}{l}\text { 5PM; } \\
\text { BSDF peak extraction }\end{array}$ & $\begin{array}{l}\text { Low-resolution BSDF for 3PM part } \\
\text { and high-resolution BSDF for } \\
\text { accurate direct contribution }\end{array}$ \\
\hline
\end{tabular}




\section{Discussion}

There are several open issues for discussion when it comes to the BSDF characterization of daylight systems and their application in lighting simulation tools. A few of these discussion points are mentioned here, knowing that this list is not exhaustive.

\subsection{Intended uses of BSDF data}

The procedures proposed in this document support the evaluation of energy efficiency and visual discomfort. Further work is needed to determine whether these procedures are sufficient for modelling view, privacy, black out capabilities, or other qualities desired by the consumer. Additional work is needed to determine if spectrally resolved BSDFs are needed to evaluate the non-visual, healthrelated performance of daylighting products.

\subsection{Analytical models}

As mentioned in the introduction, this white paper does not discuss methods for deriving analytical BSDF models from measured goniophotometer data such as e.g. the model developed in [Kotey 2009] from spectrophotometer data for solar heat gain simulations of fabrics. However, there is considerable importance and urgency for further research to develop adequate methods to derive such analytical models. This issue is particularly relevant for products that are available in hundreds or thousands of permutations of design, shape, and color (e.g., fabrics). Analytical models will enable generation of extensive databases that include the most relevant shading and daylight systems. There is an open question as to who should be responsible for creating such parametric models and how they can be verified sufficiently against measurements.

\subsection{Measurement quality}

There are only a handful of institutions that possess the high-quality instruments and facilities needed to make accurate, high-resolution measurements of microscopic systems that exhibit specular transmission or reflectance properties. There are alternate laboratories that can produce data with lower resolution and dynamic range, but the impacts of this less accurate data on simulated performance are largely unknown [Krehel 2015].

To meet industry's urgent demand for BSDF data, a practical solution is needed that balances the need for high quality measured data against "acceptable" levels of error. The following questions are still under discussion by the scientific community:

- A timeframe for generating a publicly available, international BSDF database needs to be defined with an agreement on what constitutes a minimal acceptable level of quality and/or error, e.g., in $\mathrm{N}$ years, a raw measurement database will be available to the public with sufficient accuracy to produce high-resolution BSDF datasets for M classes of products.

- Alternatively, a BSDF database could be made available today with XML tags indicating intended use for the BSDF data and its accuracy, enabling the end user to make the final decision on uses of the data, e.g., XML tag indicating that the raw measured data are sufficient for producing low resolution data and/or qualifiers indicating that the data are useful for daylight and solar heat gain calculations but insufficient for glare analysis. Such tags are necessary because "high-resolution" tabulated BSDFs can be produced by end users even when there are insufficient measured data to support generation of an accurate highresolution BSDF. 


\subsection{Measurement limitations}

To measure full or partial specular transmission and reflection for daylight glare analysis, a goniophotometer must be able to resolve peaks to within $0.5^{\circ}$ (apex angle of the sun) with sufficient dynamic range. Goniophotometers are, however, often configured for general applicability (e.g., a balance of moderate acquisition speed, signal-to-noise ratio, and directional resolution) rather than near-specular measurements of high resolution [Apian-Bennewitz 2010]. This limits most measurements to $\geq 1^{\circ}$ angular resolution in current practice, where no further post-processing can separate light scattering by the sample from the instrument signature [Ferrero 2020]. To address this limitation, the peak extraction algorithm (i.e., Radiance "aBSDF" material) replaces the BSDF coefficient(s) in the specular direction with an adjusted value for a solid angle of light source (i.e., $0.5^{\circ}$ for the sun).

The question of whether highly resolved measurements in the specular direction are necessary for some classes of products is as of yet unresolved (e.g., fabrics). If an algorithm can extract sufficiently accurate values from a low resolution BSDF dataset, then the standards for measurement equipment could be lowered (i.e., lower angular resolution and dynamic range) and the number of qualifying institutions or laboratories could be increased, speeding up the process of populating the BSDF database. On the other hand, for some products, we might need a high resolution BSDF dataset to resolve not only the peak but also how luminance falls off from the peak to predict glare accurately. Further investigation is required to evaluate this option and understand potential ramifications.

An issue open for discussion is also the data near grazing angles. Measurement of values for incidence angles close to grazing are challenging, values at high incident angles (as proposed at e.g. $82.5^{\circ}$ ) are often unreliable. Interpolation / extrapolation routines are also needed to handle this area accordingly. Also, often the illuminated area extends beyond the unobstructed area of the sample and varies with the phi angle. There may also be relevant obstructions regarding the outgoing beams in both hemispheres.

Even at normal incidence $\left(0^{\circ}\right)$ there are limitations [Grobe 2018b]. It is often experimentally impossible for reflectance measurements (the detector obscures the light source) and can even be problematic for transmittance measurements due to multiple reflections between a smooth planar sample and the detector.

An additional question is the minimum number of measured incident angles needed to accurately characterize a system. Even the nine incident angles proposed for an isotropic, symmetric system is a significant cost burden on manufacturers. The question of whether analytical models supported by a single normal incidence measurement is sufficient is as yet unresolved.

\subsection{Qualifying or certifying BSDF data}

For many types of systems, BSDFs have been and continue to be generated in-house by engineering consultants and manufacturers. For regulatory agencies implementing building energy efficiency standards, there is a need to have products characterized or certified to a standard level of quality. To encourage innovation, BSDF generation standards must support equitable comparisons and differentiation between products.

Rigorous round robin tests have been performed amongst research institutions to develop and evaluate measurement procedures and assess limits of accuracy. Further discussion is needed to determine:

- whether different stakeholders should be allowed to participate in the generation of and sharing of BSDFs publicly while protecting consumer interests.

- Should BSDFs generated by an unqualified consultant or manufacturer be allowed to be included in an international BSDF database (e.g., differentiate data entries as certified versus non-certified)? 
- Should different standards be applied to microscopic BSDF measurements than simulations generated with macroscopic geometry? How can protected geometric data be vetted?

- Should there be procedures or an impartial organization (e.g., Attachments Energy Rating Council (AERC) in the US, European Solar-Shading Organization (ES-SO) in Europe) in place for qualifying a consultant or manufacturer through round robin testing?

LBNL has established a publicly available, free international glazing database [IGDB 2020] and is in the process of establishing a similar database for shading products [CGDB 2020] (as of 2020, the CGDB database is largely focused on supporting solar heat gain analysis of residential shading products). Manufacturers must pay a fee for product characterization by independent laboratories and certification entries into the database. Certified data are labelled as such in the database (but not yet explicitly qualified based on low- or high-resolution). Regional data aggregators are designated to collect and verify data from sources in their respective regions (e.g., EU, China, South America, etc.) before inclusion in the database. The data must be checked and verified periodically to ensure that the data are representative as changes are made in manufacturing.

Within the framework of the bilateral ICON project between LBNL and Fraunhofer, the ICON Knowledge Data Base (IKDB) is being prepared to allow access to optical data, including BSDF, not only from the IGDB and CGDB but also from the data bases of shading manufacturers and accredited laboratories in different regions of the world.

For shading and daylighting systems for the commercial building sector, a different model may be useful to consider. Some lighting simulation packages (e.g., LightStanza, DIALux, Relux) provide a few BSDF samples in their software internal databases and single manufacturers also offer BSDFs on their websites. There is considerable innovation in the commercial sector: in some cases, BSDFs are generated for unique systems that have been designed (and later manufactured) for a specific project. Design and engineering staff currently use BSDFs for generic descriptions of products in the early design stage to facilitate rapid decision-making then make final purchasing decisions in the later construction documents stage. Designers may wish to create an open-access database for early design, where BSDFs are freely shared without prior certification (and with accompanying legal disclaimers). For final specification, certified BSDFs could then be used for detailed analysis and code compliance. The ramifications on analysis quality due to the diversity of these sources needs to be discussed.

\subsection{Meta information in BSDF files}

Upon completion of measurements and generation of the final BSDF data set, the source and conditions of the measurements must be documented and included with submittals to publicly available BSDF libraries. This is particularly important in cases where high-resolution BSDF could be erroneously produced from a low-resolution measured dataset (e.g., measurements at normal incidence are combined with an analytic model to produce full BSDF datasets). It would be helpful to develop a common way to describe how data was created.

Information should include for example goniophotometer type and model, bench set up conditions including what was designated as the front and back surfaces of the system and its angular rotation, incident angles measured, minimum angular resolution in the exiting direction and dynamic range of the measurements, data acquisition software version, date, and institution performing the measurements. Moreover, the database should allow access to the raw measurement data for full disclosure and confirmation. Further discussion is needed to define how this information should be documented and integrated into the database. 


\subsection{Limitations of geometrical models}

Export functions Geometrical errors can happen by exporting the model from the BIM authoring software.

Data availability Manufacturers may have the 3D model of their products but may not be able to export it in the right format or choose not to do so to preserve trade secrets.

Data reliability The geometrical data usually used is theoretical. It only works on the basis that the manufactured product closely conforms to the ideal design, which is often not the case.

Data quality It is currently difficult to ensure that the geometrical data, even measured from the manufactured product, is sufficiently accurate. It is hard to predict the geometrical accuracy needed for a model.

Geometrical details Shading systems can have multiple small sized holes and cords.

\subsection{Special considerations for glare evaluations}

The proposed characterization types for various kinds of daylight systems and different daylight performance metrics in Section 6 are based on general considerations for illuminance and luminancebased evaluations. As a special case, but one that is essential, discomfort glare metrics are primarily based on glare source luminance for the contrast effect (e.g., UGR, DGI), sometimes supplemented by the vertical illuminance at the eye for the saturation effect (e.g., CGI, DGP). While the illuminance as an integral value is less critically dependent on high-resolution BSDF data, the key issue is how to accurately model glare source luminance values.

For daylight systems this means that especially sunlight - no matter if transmitted, scattered, or redirected - needs to be predicted at highest accuracy. Therefore, high-resolution BSDFs or peak extraction strategies are required. For example, results from sensitivity analyses [Pedersen and Rasmussen 2019, Geisler-Moroder 2019] indicate that tensor tree BSDFs with a maximum resolution of 4096 x 4096 are appropriate for DGP evaluations. Using high-resolution BSDFs in turn challenges the Monte Carlo sampling in a backward raytracing approach to adequately resolve the peaks in the distribution. The peak extraction method (cf. Section 6) enables simulation of glare sources with their assumed real size (e.g., sun orb), thus requiring lower BSDF resolutions, but current implementations of this method are limited to direct-through contributions.

Even for the simplified eDGPs (as e.g., implemented in the Fener tool [Abravesh 2019]), where lowresolution BSDF datasets are used to calculate the vertical illuminance at the eye, a precise model is needed for the contrast evaluation. It is based on a simplified rendered image of the field of view (without diffuse bounces) where the direct-direct transmittance is crucial and thus a high-resolution BSDF is required. An alternative would be to use a proxy model where the computational effort allows (i.e., directly using the underlying model which would be used to generate the BSDF data with a virtual goniophotometer, e.g., geometry model as in Section 5.1, Step 2, or Radiance BRTDfunc model as in Section 5.3, Step 3). 
- Abravesh, M., Bueno, B., Heidari, S., Kuhn, T. E. (2019), A method to evaluate glare risk from operable fenestration systems throughout a year, Building and Environment 160, S. 106213, DOI: 10.1016/j.buildenv.2019.106213.

- Andersen, M., Roecker, C., Scartezzini, J.-L. (2005), Design of a time-efficient videogoniophotometer combining bidirectional functions assessment for transmission and reflection, Solar Energy Materials and Solar Cells 88 (1): 97-118.

- Apian-Bennewitz, P. (2010). New scanning gonio-photometer for extended BRTF measurements, Proceedings SPIE, 7792 Reflection, Scattering, and Diffraction from Surfaces II: 779200--779200.

- Ashikhmin, M., Shirley, P. (2000), An Anisotropic Phong BRDF Model, Journal of Graphics Tools 5 (2): 25-32.

- Blinn, J.F. (1977), Models of light reflection for computer synthesized pictures, ACM SIGGRAPH Computer Graphics (11) 2: 192-198.

- Bourgeois, D., Reinhart, C.F., Ward, G. (2008), Standard Daylight Coefficient Model for Dynamic Daylight Simulations, Building Research and Information 36 (1): 68-82.

- CEN (2018), EN 12216:2018, Shutters, external blinds, internal blinds - Terminology, glossary and definitions.

- CEN (2020), EN 14500:2020, Blinds and shutters - Thermal and visual comfort - Test and calculation methods, (status as of 2020-09-03: approved).

- CGDB (2020), Complex Glazing Database (CGDB), (retrieved online 2020-02-25).

- CIE 108-1994 (1994), Guide to Recommended Practice of Daylight Measurement, Standard by Commission Internationale de l'Eclairage.

- Cook, R.L., Torrance, K.E. (1981), A Reflectance Model for Computer Graphics, Computer Graphics, 15(3).

- Curcija, S. Vidanovic, S., Hart, R., Jonsson, J., Powles, R., Mitchell, R. (2018), WINDOW Technical Documentation, Windows and Envelope Materials Group Lawrence Berkeley National Laboratory Berkeley, California 94720 (retrieved online 2020-02-06).

- DIN (2017), DIN 5032-7: Lichtmessung - Teil 7: Klasseneinteilung von Beleuchtungsstärkeund Leuchtdichtemessgeräten.

- Ferrero A. (2020), Theoretical evaluation of the impact of finite intervals in the measurement of the bidirectional reflectance distribution function, Journal of Coatings Technology and Research 17: 81-90.

- Geisler-Moroder, D., Dür, A. (2010), A New Ward BRDF Model with Bounded Albedo, Computer Graphics Forum 29 (4) (Proc. EGSR 2010): 1391-1398.

- Geisler-Moroder, D., Lee, E.S., Ward, G.J. (2017), Validation of the Five-Phase Method for Simulating Complex Fenestration Systems with Radiance against Field Measurements, Building Simulation 2017, San Francisco, August 7-9, 2017.

- Geisler-Moroder D. (2019), BSDF daylight system characterization - sensitivity and requirements to resolution, 20th International Radiance Workshop 2019, New York, USA, August 21-23, 2019 (retrieved online 2020-02-24).

- Gossen (2019), Kompendium der Lichtmesstechnik, (retrieved online 2020-02-20).

- Grobe, L.O. (2017), Computational combination of the optical properties of fenestration layers at high directional resolution, Buildings 2017, 22.

- Grobe, L.O. (2018a), High Resolution Complex Glazing Library, Research project at Lucerne University of Applied Sciences and Arts, 2016 -2018, (retrieved online 2020-02-21).

- Grobe L.O. (2018b), Characterization and data-driven modeling of a retro-reflective coating in Radiance, Energy and Buildings 162: 121-133.

- Grobe, L.O. (2019), Photon mapping in image-based visual comfort assessments with BSDF models of high resolution, Journal of Building Performance Simulation 12 (6): 745-758.

- IEA International Energy Agency (1999), Measurement of Luminous Characteristics of Daylighting Materials, A Report of IEA SHC TASK 21 / ECBCS ANNEX 29 (retrieved online 2020-02-24).

- IEA International Energy Agency (2020), BSDF daylight system characterization, A Technical Report of IEA SHC Task 61 / EBC Annex 77, Draft. 
- IEA International Energy Agency (2020), IEA SHC Task 61 / EBC Annex 77: Integrated Solutions for Daylighting and Electric Lighting, http://task61.iea-shc.org/.

- IGDB (2020), International Glazing Database (IGDB), (retrieved online 2020-02-25).

- Kurt, M. (2018), A Survey of BSDF Measurements and Representations, Journal of Science and Engineering, Volume 20, Issue 58, 2018.

- Light Tec (2020), Reflet 180S, (retrieved online 2020-02-06).

- Klems, J.H. (1994), A new method for predicting the solar heat gain of complex fenestration systems, ASHRAE Transactions, 100 (1): 1065-1086.

- Kotey, N.A., Wright, J.L., Collins, M.R. (2009), Determining off-normal solar optical properties of roller blinds, ASHRAE Transactions 115 (1):145-154.

- Krehel, M., Kämpf, J., Wittkopf, S. (2015), Characterisation and modelling of advanced daylight redirecting systems with different goniophotometers, in CISBAT 2015, Lausanne, Switzerland.

- Krywonos, A.; Harvey, J. E.; Choi, N. (2011), Linear systems formulation of scattering theory for rough surfaces with arbitrary incident and scattering angles, J. Opt. Soc. Am. A 28, 11211138.

- Ladybug Tools (2020), BSDF Viewer, (retrieved online 2020-09-16).

- Lee, E.S., Geisler-Moroder, D., Ward, G. (2018), Modeling the direct sun component in buildings using matrix algebraic approaches: Methods and validation, Solar Energy 160: 380395.

- Lewis, R.R. (1994), Making shaders more physically plausible, Computer Graphics Forum (Eurographics '94 Conference Issue) 13 (3): 1-13.

- LightTools (2020), LightTools Illumination Design Software, (retrieved online 2020-09-16).

- McNeil, A. (2011), On the sensitivity of daylight simulations to the resolution of the hemispherical basis used to define bidirectional scattering distribution functions, LBNL Technical deliverable, (retrieved online 2020-02-24).

- McNeil, A. (2013), BSDFViewer: A utility for interactive exploration of BSDF datasets, software available at http://www.radiance-online.org/download-install/bsdf-viewer (retrieved online 2020-02-20).

- McNeil, A. (2013), The Five-Phase Method for Simulating Complex Fenestration with Radiance, Radiance Tutorial, (retrieved online 2020-02-06).

- McNeil, A., Jonsson, C.J., Appelfeld, D., Ward, G., Lee, E.S. (2013), A validation of a raytracing tool used to generate bi-directional scattering distribution functions for complex fenestration systems. Sol. Energy 98, 404-414.

- McNeil, A., Lee, E.S. and Jonsson, J.C. (2017), Daylight performance of a microstructured prismatic window film in deep open plan offices, Building and Environment 113: 280-297.

- Mitchell, R., Kohler,C., Klems, J., Rubin, M., Arasteh, D. (2006), WINDOW 6.1 / THERM 6.1 Research Version User Manual, Lawrence Berkeley National Laboratory, (retrieved online 2020-02-12).

- Nicodemus, F.E., Richmond, J.C., Hsia, J.J., Ginsberg, I.W., Limperis, T. (1977), Geometrical Considerations and Nomenclature for Reflectance. NBS Monograph 160, U. S. Dept. of Commerce.

- pab advanced technologies Ltd (2020), pab Ltd Gonio-Photometer II, (retrieved online 202002-06).

- Pedersen, M., Rasmussen, F. (2019), A Sensitivity Analysis on the Effect of BSDF Resolutions for Solar Shading Devices Coupled with Practical Measurements, Master Thesis, Technical University of Denmark.

- Phong, B.T. (1975), Illumination for computer generated pictures, Communications of the ACM, Volume 18, Issue 6, pp.311-317.

- Radsite radiance-online.org (2020a), Radiance Source Code, Head Release, (retrieved online 2020-02-06).

- Radsite radiance-online.org (2020b), genBSDF manpage, (retrieved online 2020-12-02).

- Roos, A., Polato, P., Van Nijnatten, P.A., Hutchins, M.G., Olive, F. and Anderson, C. (2001), Angular-dependent optical properties of low-e and solar control windows-: Simulations versus measurements. Solar Energy 69: 15-26.

- Schwanengel, C. (2010), Gegenüberstellung von Messtechniken zur Messung von Lichtstärkeverteilungen und Lichtstärkeverteilungsausschnitten, TechnoTeam Bildverarbeitung $\mathrm{GmbH}$, August 2010, Table 3.1, page 34. 
- Shirley, P., Chiu, K. (1977), A Low Distortion Map between Map and Square, Journal of Graphics Tools 2(3).

- Ward, G. (1996), The Materials and Geometry Format, (retrieved online 2020-02-12).

- Ward, G. (2011), Using the New Radiance BSDF Material Primitive, 10th International Radiance Workshop, Berkeley, CA, USA, August 2011, (retrieved online 2020-11-23).

- Ward, G. (2018), Radiance Updates, 17th International Radiance Workshop, Loughborough, UK, September 2018, (retrieved online 2020-02-06).

- Ward, G., Kurt, M., Bonneel, N. (2014), Reducing anisotropic BSDF measurement to common practice. Proceedings of the Eurographics 2014 Workshop on Material Appearance Modeling: Issues and Acquisition (MAM '14).

- Ward, G., McNeil, A. (2011), A Variable-resolution BSDF Implementation, 10th International Radiance Workshop, Berkeley, CA, USA, August 2011.

- Ward, G., Mistrick, R., Lee, E.S., McNeil, A., Jonsson, J. (2011), Simulating the Daylight Performance of Complex Fenestration Systems Using Bidirectional Scattering Distribution Functions within Radiance, LEUKOS, Vol. 7, No. 4.

- Wienold, J., Iwata, T., Sarey Khanie, M., Erell, E., Kaftan, E., Rodriguez, R. G., et al. (2019), Cross-validation and robustness of daylight glare metrics, Lighting Research \& Technology 51 (7), S. 983-1013, DOI: 10.1177/1477153519826003.

- Wienold, J. (2009), Dynamic daylight glare evaluation, Eleventh International IBPSA Conference, Glasgow, 27-30 July.

- Wienold, J., Christoffersen, J. (2006), Evaluation methods and development of a new glare prediction model for daylight environments with the use of CCD cameras, Energy and Buildings 38 (7), S. 743-757, DOI: 10.1016/j.enbuild.2006.03.017.

- Wienold, J.,Kuhn, T. E., Christoffersen, J., Andersen, M. (2017), Annual glare evaluation for fabrics, Proceedings PLEA 2017, Edinburgh, July 3-5. Additional material: https://infoscience.epfl.ch/record/231231

- WINDOW (2020), WINDOW - A computer program for calculating total window thermal performance indices, (retrieved online 2020-02-25). 